\title{
Evidence Supporting the Safety of Pegylated Diethylaminoethyl-Chitosan Polymer as a Nanovector for Gene Therapy Applications
}

This article was published in the following Dove Press journal: International Journal of Nanomedicine

\author{
Elsa Patricia Rondon' \\ Houda Abir Benabdoun' \\ Francis Vallières' \\ Maicon Segalla Petrônio (D) ${ }^{2}$ \\ Marcio José Tiera (D) ${ }^{2}$ \\ Mohamed Benderdour' \\ Julio Cesar Fernandes (D) \\ 'Orthopedic Research Laboratory, \\ Hôpital Du Sacré-Cœur De Montréal, \\ Université De Montréal, Montréal, \\ Québec, Canada; ${ }^{2}$ Institute of \\ Biosciences, Humanities and Exact \\ Sciences, Department of Chemistry and \\ Environmental Sciences, UNESP-São \\ Paulo State University, São José Do Rio \\ Preto, São Paulo State, Brazil
}

Purpose: Diethylaminoethyl-chitosan (DEAE-CH) is a derivative with excellent potential as a delivery vector for gene therapy applications. The aim of this study is to evaluate its toxicological profile for potential future clinical applications.

Methods: An endotoxin-free chitosan $(\mathrm{CH})$ modified with DEAE, folic acid (FA) and polyethylene glycol (PEG) was used to complex small interfering RNA (siRNA) and form nanoparticles $\left(\mathrm{DEAE}_{12}-\mathrm{CH}-\mathrm{PEG}-\mathrm{FA}_{2} / \mathrm{siRNA}\right)$. Based on the guidelines from the International Organization for Standardization (ISO), the American Society for Testing and Materials (ASTM), and the Nanotechnology Characterization Laboratory (NCL), we evaluated the effects of the interaction between these nanoparticles and blood components. In vitro screening assays such as hemolysis, hemagglutination, complement activation, platelet aggregation, coagulation times, cytokine production, and reactive species, such as nitric oxide (NO) and reactive oxygen species (ROS), were performed on erythrocytes, plasma, platelets, peripheral blood mononuclear cells (PBMC) and Raw 264.7 macrophages. Moreover, MTS and LDH assays on Raw 264.7 macrophages, PBMC and MG-63 cells were performed.

Results: Our results show that a targeted theoretical plasma concentration (TPC) of $\mathrm{DEAE}_{12}$

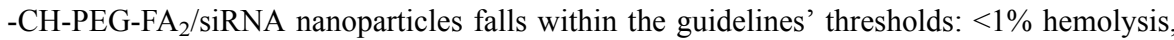
$2.9 \%$ platelet aggregation, no complement activation, and no effect on coagulation times. ROS and NO production levels were comparable to controls. Cytokine secretion (TNF- $\alpha$, IL6, IL-4, and IL-10) was not affected by nanoparticles except for IL-1 $\beta$ and IL-8. Nanoparticles showed a slight agglutination. Cell viability was $>70 \%$ for TPC in all cell types, although LDH levels were statistically significant in Raw 264.7 macrophages and PBMC after 24 and $48 \mathrm{~h}$ of incubation.

Conclusion: These $\mathrm{DEAE}_{12}-\mathrm{CH}-\mathrm{PEG}-\mathrm{FA}_{2} / \mathrm{siRNA}$ nanoparticles fulfill the existing ISO, ASTM and NCL guidelines' threshold criteria, and their low toxicity and blood biocompatibility warrant further investigation for potential clinical applications.

Keywords: chitosan, nanoparticles, siRNA, biocompatibility assays, gene therapy, toxicity

\section{Introduction}

Biocompatibility studies on nanoformulations for biomedical applications have been a subject of increasing interest in the last decades, as they are being submitted to the Food and Drug Administration (FDA) and marketed. A review of the 51 nanomedicines currently approved by the FDA, and some of the 77 products undergoing clinical trials have been the subject of a previous study. ${ }^{1}$ Pursuing the preclinical development of a new formulation depends not only on its efficacy, but
Correspondence: Julio Cesar Fernandes Tel +l 5|4-338-2222 Ext. 2489

Email julio.c.fernandes@umontreal.ca 
also on its safety. Nowadays, regulatory agencies, standards development organizations, and laboratory research teams develop screening methodologies to improve the assessment of the estimated biological response to a specific nanomaterial.

Over the past decade, our laboratory has developed a modified chitosan $(\mathrm{CH})$ with excellent potential for gene therapy applications and evaluated its different therapeutic uses. $^{2} \mathrm{CH}$, a natural polymer composed of glucosamine units, showed good biocompatibility and biodegradability properties. ${ }^{3}$ Its versatility allows it to be used in several fields, including wastewater treatment, agriculture, textiles, food protection and cosmetics. ${ }^{4}$ It has a tremendous potential for biomedical and pharmaceutical applications as a drug delivery vehicle, ${ }^{5}$ in vaccine systems, ${ }^{6}$ tissue engineering, wound dressing, diagnosis, ${ }^{7}$ and gene therapy, ${ }^{8}$ among others.

In terms of toxicity outcomes, $\mathrm{CH}$ and its derivatives, show low blood toxicity, as they generally do not induce significant hemolysis and do not affect the complement activation system. ${ }^{9-11}$ However, the data on blood compatibility are contradictory. There were reports that this polymer can induce hemagglutination, ${ }^{9}$ or impact platelet activation and clotting time, ${ }^{10}$ depending on its physicochemical characteristics. Cell viability can also be differentially affected, depending on $\mathrm{CH}$ modifications and the cell type studied. For example, HUVEC cell line survival increases when incubated with a CH-heparin nanoparticles coating on anodized NiTi (nickel-titanium), ${ }^{12}$ while a glycol CH-nanogel induces slight cell toxicity on Raw 264.7 macrophages, 3T3 fibroblasts and HMEC. ${ }^{13}$ Similarly, in L929 cells, viability is not affected by lauroyl sulfated $\mathrm{CH}$ microparticles, ${ }^{11}$ whereas $\mathrm{CH} /$ polyglutamic acid hollow spheres affect the viability of HUVEC and HUASMC, in a cell, time, size, and chargedependent manner. ${ }^{10}$

The physicochemical differences in all these nanoformulations explain most of the variability in hematocompatibility and cytotoxicity responses. Another factor is the heterogeneity in screening protocols, coupled with the general assumption that $\mathrm{CH}$ is biocompatible, resulting in a limited number of reports on its hemagglutination and oxidative stress response. Finally, the lack of information on endotoxin contamination in $\mathrm{CH}$ formulations makes it difficult to interpret results from cytokine up-regulation, as the presence of endotoxins alone can induce the production of important pro-inflammatory mediators, such as tumor necrosis factor alpha (TNF- $\alpha$ ) and interleukin-6 (IL-6). ${ }^{14}$ These facts underscore the need to follow available guidelines when evaluating the toxicological profile of a newly synthesized nanoparticle.

A good starting point for biocompatibility studies are the guidelines from the International Organization for Standardization (ISO), the American Society for Testing and Materials (ASTM), and the Nanotechnology Characterization Laboratory (NCL), which provide protocols and recommendations to perform preclinical studies on nanoformulations. Reviews of standards, guidelines and agencies are available in several reports. ${ }^{15-18}$

Our goal is to design safe and functionalized nanoparticles that release their therapeutic cargo, namely small interfering RNA (siRNA), to target cells with minimal toxicity to tissues. As we aim for a parenteral administration, we decided to use the existing guidelines to achieve validated outcomes before proceeding to a clinical application. The present study systematically evaluates the safety of a pegylated diethylaminoethyl $\mathrm{CH}\left(\mathrm{DEAE}_{12}-\mathrm{CH}-\right.$ PEG-FA 2 ), with or without siRNA-SSB complexation. This derivative showed a high in vitro transfection efficiency on varied cell lines ${ }^{19}$ and its in vivo therapeutic efficacy was demonstrated in a murine collagen antibodyinduced arthritis model. ${ }^{2}$ Among the assays proposed by ISO 10,993-4:2009, ${ }^{20}$ ISO/TR 16,197, ${ }^{17}$ ASTM F1903, ${ }^{21}$ ASTM E56.03 committee, ${ }^{22}$ and NCL protocols, ${ }^{23}$ the following were chosen: endotoxin contamination, physicochemical characterization, cytotoxicity assay, hemotoxicity (hemolysis, hemagglutination, complement activation, platelet aggregation and coagulation tests), inflammatory response (cytokines) and oxidative stress response (reactive oxygen species (ROS) and nitric oxide (NO)).

\section{Materials and Methods Materials}

Medical grade deacetylated CH (ChitoClear ${ }^{\circledR}$, 43,010, 270 $\mathrm{kDa}$ ) was obtained from Primex ehf (Siglufjordur, Iceland). RPMI 1640 medium, EMEM medium, fetal bovine serum (FBS), $\quad 0.25 \% \quad$ trypsin-EDTA solution, penicillinstreptomycin $(\mathrm{P} / \mathrm{S})$ and lymphocyte separation medium (LSM) were purchased from WISENT Bioproduct Inc (Montréal, Qc, Canada). siRNA-SSB (GenBank accession number NM_009278) with the oligonucleotide sequence: antisense 5'-uuacauuaaagucuguuguTT-3'; and sense 5'acaacagacuuuaauguaaTT-3' (as mentioned by Abrams et al, ${ }^{24}$ and Seitzer et al) ${ }^{25}$ with a $2^{\prime}$-O-Me-rA (rC, rG, rU) modification, was purchased from Alpha DNA S.E.N.C. (Montréal, Qc, Canada). Pyrogen-free consumables (Biosphere ${ }^{\circledR}$ plus 
certified) were purchased from Sarstedt (Montréal, Qc, Canada). Other chemicals or solutions, if not otherwise stated, were purchased from Sigma Aldrich Canada (Oakville, ON, Canada). Raw 264.7 macrophage and MG-63 cells were purchased from American Type Culture Collection (ATCC, Manassas, VA, USA).

\section{Ethics Committee}

Experiments with human blood were approved by the Hôpital du Sacré-Cœur de Montréal - Centre Intégré Universitaire de Santé et de Services Sociaux du Nord de l'Ile de Montréal (CIUSSS NIM) - Research Ethics Committee (Protocol \# 2017-1462). Informed consent was obtained from healthy donor volunteers who were not ill nor under medication at the time of blood sample collection. PBMC were collected from healthy volunteers who provided blood samples. The CIUSSS NIM Research Ethics Committee approved the use of these cells and the corresponding experimental procedures (Protocol \# 2017-1462).

\section{Synthesis of $\mathrm{DEAE}_{12}-\mathrm{CH}-\mathrm{PEG}-\mathrm{FA}_{2}$}

Groups of diethylaminoethyl (DEAE), polyethylene glycol (PEG - $3 \mathrm{kDa}$ spacer) and folic acid (FA) were grafted to the $\mathrm{CH}$ structure. $\mathrm{DEAE}_{12}-\mathrm{CH}$ conjugation was prepared as described by Oliveira et al. ${ }^{26}$ Final conjugation of $\mathrm{DEAE}_{12}-\mathrm{CH}$ and PEG-FA was performed as reported by Cho et $\mathrm{al}^{27}$ with slight modifications, described in our previous study. ${ }^{28}$

\section{Limulus Amebocyte Lysate (LAL) Assay}

All the materials used for this test were purchased pyrogen-free. One sample from each stage of synthesis, prepared at $1 \mathrm{mg} / \mathrm{mL}$, was analyzed for the presence of endotoxins by LAL assay $(88,282$, Thermo Fisher, SaintLaurent, Qc, Canada), according to NCL method STE$1.1^{29}$ and the manufacturer's instructions. The kit's detection levels were in the $0.1 \mathrm{EU} / \mathrm{mL}$ to $1 \mathrm{EU} / \mathrm{mL}$ range.

\section{Characterization of Modified CH}

Polymer characterization was performed as described in our previous studies. ${ }^{26,28}$ Nuclear magnetic resonance $\left({ }^{1} \mathrm{H}-\mathrm{NMR}\right)$ was used to assess the degree of $\mathrm{CH}$ deacetylation (DDA) and the DEAE percentage incorporated into the polymer structure. The percentage of PEG-FA incorporated was calculated by measuring FA absorbance $\left(\lambda_{363 \mathrm{~nm}}\right)$ in a nanophotometer, using CH-DEAE as a blank. An extinction coefficient of $6165 \mathrm{M}^{-1} \mathrm{~cm}^{-1}$
$(\mathrm{FA})^{28}$ was used for calculations. The molecular weight (MW) of the $\mathrm{CH}$ polymer was evaluated by gel permeation chromatography (GPC). Additional Information about DEAE $_{12}$-CH-PEG-FA 2 characterization is described in our previous study. ${ }^{19}$

\section{Nanoparticle Preparation in DPBS pH 7.2} DEAE $_{12}$-CH-PEG-FA 2 was dissolved overnight in a 0.1 M HCL solution, then heated at $50^{\circ} \mathrm{C}$ for 30 min, adjusted with Dulbecco's Phosphate-Buffered Saline (DPBS) to the desired final concentration, and finally filtered with a 0.45 $\mu \mathrm{m}$ polyether sulfone membrane filter. To prepare $\mathrm{DEAE}_{12}$ -CH-PEG-FA 2 /siRNA-SSB nanoparticles, siRNA-SSB and modified $\mathrm{CH}$ stock solutions were added to DPBS and vortexed immediately at moderate speed for $1 \mathrm{~min}$. Nanoparticles were always freshly prepared prior to each experiment.

\section{Characterization of DEAE $12-\mathrm{CH}-\mathrm{PEG}-\mathrm{FA}_{2}$ /siRNA Nanoparticles in DPBS pH 7.2}

The size and charge (zeta potential) were evaluated with a Zetasizer Nano ZS90 (Malvern Instruments Ltd., Malvern, UK), using a $1 \mathrm{~mL}$ nanoparticle solution containing $0.02 \mathrm{mM}$ of siRNA. Size versus (vs) time studies were performed to analyze the particle's stability for $24 \mathrm{~h}$. DEAE 12 -CH-PEG$\mathrm{FA}_{2} /$ siRNA nanoparticles at amino groups/phosphate groups $(\mathrm{N} / \mathrm{P})$ ratios of 5:1, 10:1, 15:1, 20:1, 30:1 and 40:1 were prepared as indicated above. The $\mathrm{DEAE}_{12}$-CH-PEG-FA 2 /siRNA nanoparticle formation was evaluated by $2 \%$ agarose gel electrophoresis, by loading $10 \mu \mathrm{L}$ of nanoparticle solution with $0.5 \mu \mathrm{g}$ of siRNA.

\section{Nanoparticle Concentrations Selection for in vitro Assays and Controls}

DEAE $_{12}$-CH-PEG-FA $2 /$ siRNA nanoparticle concentrations were chosen according to a theoretical therapeutic dose for their future use in vivo. Thus, a theoretical plasma concentration (TPC) for in vitro assays was calculated, based on NCL recommendations ${ }^{30}$ and FDA directives. ${ }^{31}$ Our previous work showed the efficiency of a $50 \mu \mathrm{g}$ siRNA-TNF $\alpha$ /intraperitoneal injection/mouse in a mouse model of arthritis. $^{2}$ These results and those in the literature gave us a framework to determine the dose that we could test in vivo for a future intravenous administration in a mouse model. Thereby, the dose of $30 \mu \mathrm{g}$ siRNA-SSB/intravenous injection/mouse $(1.5 \mathrm{mg} / \mathrm{kg}$, for a $20 \mathrm{~g}$ mouse) was chosen as the target dose to be complexed with DEAE $_{12}-\mathrm{CH}-\mathrm{PEG}-\mathrm{FA}_{2}$. 
Based on NCL guidelines, ${ }^{30}$ an equivalent human dose $(0.1219 \mathrm{mg} / \mathrm{kg})$ was calculated and the corresponding TPC (1.52 $\mu \mathrm{g} / \mathrm{mL}$ siRNA-SSB). Table 1 summarizes the concentrations used for in vitro assays.

This study evaluates the safety of our pegylated diethylaminoethyl $\mathrm{CH}\left(\mathrm{DEAE}_{12}-\mathrm{CH}-\mathrm{PEG}-\mathrm{FA}_{2}\right)$ with or without siRNA-SSB complexation. Positive and negative controls were used in each assay to confirm the cells' ability to respond to a given substance. Cell-free particle controls were conducted to verify nanoparticle interference with the assay.

\section{Cell Cytotoxicity}

This assay is based on slightly modified ASTM E2526-08 $(2013)^{32}$ and NCL GTA-2 (2015) ${ }^{33}$ guidelines. Cell viability, in response to $\mathrm{DEAE}_{12}-\mathrm{CH}-\mathrm{PEG}-\mathrm{FA}_{2} / \mathrm{siRNA}$ nanoparticles, was measured by MTS (3-(4,5-dimethylthiazol-2-yl)-5-(3-carboxymethoxyphenyl)-2-(4-sulfophenyl)2H-tetrazolium, G5421, Promega, Madison, WI, USA) and lactate dehydrogenase release (LDH, 11,644,793,001, Roche, Laval, QC, Canada) assays on human MG-63 cells, murine Raw 264.7 macrophages and human peripheral blood mononuclear cells (PBMC). Briefly, MG-63 and Raw 264.7 cells were plated in a 96-well plate at a confluence of 1.5 x $10^{4}$ cells/well (EMEM medium) and $3.5 \times 10^{4}$ cells/well (RPMI medium), respectively. Cells were incubated in $10 \%$ FBS phenol red-free medium for $24 \mathrm{~h}$ at $37^{\circ} \mathrm{C}$. Then, medium was replaced with fresh medium $(1 \% \mathrm{FBS})$ containing samples and incubated for 4,24 , and $48 \mathrm{~h}$ at $37^{\circ} \mathrm{C}$. PBMC were isolated based on NCL method ITA-10, using LSM. ${ }^{34}$ PBMC were collected, washed, resuspended in 1\% FBS RPMI 1640 medium, and incubated with samples at $2 \times 10^{5}$ cells/well in a 96-well plate. After the exposure period, MTS and LDH assays were performed according to the manufacturer's instructions, with absorbance readings at $490 \mathrm{~nm}$ in a microplate reader (EL800, Bio-Tek instruments). DPBS was used as the negative control. Hydrogen peroxide (500 $\left.\mu \mathrm{M} \mathrm{H}_{2} \mathrm{O}_{2}\right)$ and triton $\mathrm{X}-100(1 \% \mathrm{v} / \mathrm{v})$ were used as positive controls for the MTS and LDH assays, respectively. Cell-free particle interference controls were treated in the same

Table I Nanoparticle Concentrations in vitro

\begin{tabular}{|l|l|l|l|l|l|l|}
\hline & 20x & 10x & $\mathbf{5 x}$ & TPC & I/5x & I/25x \\
\hline siRNA-SSB $(\mu \mathrm{g} / \mathrm{mL})$ & 30.4 & 15.2 & 7.60 & 1.52 & 0.30 & 0.06 \\
DEAE $_{12}-\mathrm{CH}-\mathrm{PEG}-\mathrm{FA}_{2}(\mu \mathrm{g} / \mathrm{mL})$ & 324.2 & 162.1 & 81.0 & 16.2 & 3.24 & 0.64 \\
\hline
\end{tabular}

Notes: The higher concentrations represent 20, 10 and 5-fold the TPC. The lower concentrations are two serial 1:5 dilutions of TPC: 20x concentration was only used in the complement activation test.

Abbreviation: TPC, theoretical plasma concentration. experimental conditions. Cell viability and cytotoxicity were calculated with the following equations:

$$
\% \text { cell viability }=\left(\frac{\text { sample }}{\text { cell control }}\right) \times 100
$$

$\%$ total LDH leakage $=\left(\frac{\text { sample }- \text { cell control }}{\text { triton control }- \text { cell control }}\right) \times 100$

As the guidelines did not mention an acceptable threshold for the MTS assay, ISO 10,993-5 criteria were used, where a viability $<70 \%$ is considered toxic. ${ }^{35}$

\section{Hemolysis Assay}

This assay is based on ASTM E2524-08 (2013) ${ }^{36}$ with some modifications. In summary, human blood was collected in Naheparin tubes. Plasma-free hemoglobin (PFH) and total blood hemoglobin $(\mathrm{TBH})$ were determined and treated according to the procedure described in the guideline. Then, $20 \mu \mathrm{L}$ of diluted whole blood, $20 \mu \mathrm{L}$ of samples and $140 \mu \mathrm{L}$ of DPBS were incubated in microcentrifuge tubes for $3 \mathrm{~h}$ at $37^{\circ}$ C. A minus blood interference control was also prepared. Then, tubes were centrifuged for $8 \mathrm{~min}$ at $2000 \times \mathrm{g}$. The quantitative hemolysis determination was carried out by mixing 100 $\mu \mathrm{L}$ of the sample's supernatant with $100 \mu \mathrm{L}$ of cyanmethemoglobin reagent (hemoglobin reagent, Pointe Scientific, Canton, MI, USA). The absorbance was read at $490 \mathrm{~nm}$ and a standard curve $(0.025$ to $0.8 \mathrm{mg} / \mathrm{mL})$ prepared with human hemoglobin was used for calculations. Triton X-100 (10\%) and DPBS served as positive and negative controls, respectively. Percentage hemolysis was calculated with the following equation:

$$
\% \text { Hemolysis }=\frac{\text { Hemoglobin in sample }}{\text { TBHd }} \times 100
$$

Hemolysis $>5 \%$ indicates a positive hemolytic response according to ASTM guidelines. ${ }^{36}$

\section{Hemagglutination Test}

The chosen method is the one reported by Banerjee et al, ${ }^{37}$ Lima et al, ${ }^{38}$ and Stavitsky et al, ${ }^{39}$ with minor modifications. Briefly, human blood collected in Na-heparin tubes was centrifuged at 1500 RPM for $12 \mathrm{~min}$ to isolate erythrocytes. Plasma was discarded and red blood cells were washed 3 times with a $0.9 \% \mathrm{NaCl}$ solution. Finally, a $2 \%$ cell suspension in $\mathrm{NaCl}$ was prepared and incubated with nanoparticles in a 96-well U-bottom plate for $1 \mathrm{~h}$ at $37^{\circ} \mathrm{C}$. DPBS and lectin from Phaseolus vulgaris were used as 
negative and positive controls, respectively. Wells were photographed and scored according to the scale proposed by Stavitsky et al, ${ }^{39}$

" ++++ compact granular agglutinate;

+++ Smooth mat on bottom of tube with folded edges;

++ Smooth mat on bottom of tube, edges somewhat ragged;

+ Narrow ring of red around the edge of smooth mat;

\pm Smaller area of tube covered than + , and heavier ring around the edge;

- discrete red button in center at the bottom of the tube."

\section{Complement Activation Assay}

This test was performed according to NCL method ITA-5.1 $(2015)^{40}$ with some modifications. Briefly, whole human blood was drawn in tubes containing sodium citrate. Plasma was collected after blood centrifugation at $2500 \times \mathrm{g}$ for $10 \mathrm{~min}$. Then, equivalent volumes of plasma and samples were mixed and incubated for $30 \mathrm{~min}$ at $37^{\circ} \mathrm{C} .8 .1 \mathrm{Units}$ of cobra venom factor (CVF) and DPBS were used as positive and negative controls, respectively. Next, Laemmli buffer was added and tubes were heated at $95^{\circ} \mathrm{C}$ for $5 \mathrm{~min}$. Samples were finally loaded at $10 \mu \mathrm{g} / \mathrm{well}$ in an $8 \%$ SDSpolyacrylamide gel and transferred electrophoretically onto a nitrocellulose membrane for protein immunodetection. The primary antibodies deployed were the anti- $\mathrm{C} 3 / \mathrm{C} 3 \mathrm{~b}$ antibody (1:500, ab11871, Abcam, Toronto, ON, Canada), and the serum loading control anti-transferrin antibody $(1: 1000$, ab109503, Abcam, Toronto, ON, Canada). After serial washes, the primary antibodies were revealed by the corresponding HRP-conjugated secondary antibodies. According to NCL guidelines, ${ }^{40}$ a sample with $\geq 2$ folds the density of DPBS, for the C3c fragment, was considered positive.

\section{Platelet Aggregation Test}

This test was performed according to NCL method ITA$2.2(2015)^{41}$ with some modifications. Briefly, whole human blood was collected in sodium citrate tubes. Platelet-rich plasma (PRP) and platelet poor plasma (PPP) were obtained by blood centrifugation at $200 \mathrm{xg}$ for $8 \mathrm{~min}$ and $2500 \times \mathrm{g}$ for $10 \mathrm{~min}$, respectively. Then, $6 \mathrm{~min}$ runs were performed at $37^{\circ} \mathrm{C}$ in a platelet aggregation profiler (PAP-8E, Bio/Data Corporation) using $225 \mu \mathrm{L}$ of PRP and $25 \mu \mathrm{L}$ of samples. A baseline correction was performed using PPP and samples for possible particle interference. Collagen $(100 \mu \mathrm{g} / \mathrm{mL})$ and DPBS were the positive and negative controls, respectively. Non-treated PRP runs at the beginning and the end of the assay were used as internal test controls. The percentage of aggregation was calculated with the following equation, where AUC represents the area under the curve:

$$
\% \text { Aggregation }=\frac{\text { AUC sample }}{\text { AUC collagen }} \times 100
$$

A platelet aggregation $>20 \%$ was considered a positive response according to NCL Method ITA-2.1 (2015). ${ }^{42}$

\section{Plasma Coagulation Test}

This assay was carried out according to NCL method ITA12 (2015). ${ }^{43}$ Briefly, whole human blood was collected in sodium citrate tubes. Plasma was collected after blood centrifugation at $2500 \times \mathrm{g}$ for $10 \mathrm{~min}$. Then, samples were incubated with plasma in a microcentrifuge tube for 30 min at $37^{\circ} \mathrm{C}$, and finally centrifuged at $17000 \times \mathrm{g}$ for $5 \mathrm{~min}$. After exposure, activated partial thromboplastin time (APTT), prothrombin time (PT) and thrombin time (TT) were measured using the STA-R Evolution coagulometer (Diagnostica Stago). Non-treated plasma and DPBS were used as internal and negative controls, respectively. Normal limits for plasma clotting time, established by the certified clinical laboratory at Hôpital du Sacré-Cœur de Montréal, were: APTT $28 \leq 40 \mathrm{~s}$, PT $11 \leq 15 \mathrm{~s}$, and TT $14 \leq 21$ s.

\section{Cytokine Assay}

This assay was performed based on NCL method ITA-10 (2015). ${ }^{34}$ Briefly, human PBMC were re-suspended in a 10\% FBS RPMI 1640 medium. Cells ( 1 x 10\%/well) were incubated with samples for $24 \mathrm{~h}$ at $37^{\circ} \mathrm{C}$. Lipopolysaccharides (LPS, tlrl-peklps, $20 \mathrm{ng} / \mathrm{mL}$, Invivogen, San Diego, CA, USA) and DPBS were the positive and negative controls, respectively. Following exposure, supernatants were collected and centrifuged at 12,000 RPM for 15 min. Cytokines (TNF- $\alpha$, IL-1 $\beta$, IL-6, IL-8, IL-4 and IL-10) were measured with ELISA kits (PeproTech, Rocky Hill, NJ, USA).

\section{Nitric Oxide (NO) Determination}

This assay determines NO production based on NCL method ITA-7 (2015).$^{44}$ Briefly, murine Raw 264.7 cells were plated at a confluence of $1 \times 10^{5}$ cells/well in $10 \%$ FBS RPMI medium (phenol red free) and incubated for 24 $\mathrm{h}$ at $37^{\circ} \mathrm{C}$. Then, medium was replaced with fresh medium containing samples and incubated for $48 \mathrm{~h}$ at $37^{\circ} \mathrm{C}$. After 
the exposure period, supernatants were collected and centrifuged at 12,000 RPM for $10 \mathrm{~min}$. Nitrite $\left(\mathrm{NO}_{2}{ }^{-}\right)$quantitative determination was carried out with the Greiss reagent as indicated in the protocol. The absorbance was measured at $562 \mathrm{~nm}$ and a standard curve $(0.12 \mu \mathrm{M}$ to 250 $\mu \mathrm{M})$ prepared with sodium nitrite in complete medium was used for calculations. LPS (100 $\mathrm{ng} / \mathrm{mL})$ and DPBS were used as the positive and negative controls, respectively. A cell-free interference control was prepared and taken through all the experimental steps.

\section{Reactive Oxygen Species (ROS) Assay}

This test measures ROS production based on NCL method GTA-7 (2010), ${ }^{45}$ with some modifications. Briefly, murine Raw 264.7 cells were plated in a black 96-well plate at a confluence of $8.5 \times 10^{4}$ cells/well in $10 \%$ FBS RPMI medium (phenol red free) and incubated for $24 \mathrm{~h}$ at $37^{\circ} \mathrm{C}$. Then, the plate was incubated with a $20 \mu \mathrm{M}$ DCFH-DA probe solution for $30 \mathrm{~min}$. Cells were further incubated with Hanks' Balanced Salt solution (HBSS) containing the samples for $6 \mathrm{~h}$ at $37^{\circ} \mathrm{C}$. The first reading was performed at $\mathrm{t}=0$ before adding the samples, and subsequently at 0.5 , 1, 2, 3, 4, 5 and $6 \mathrm{~h}$ after exposure time. A microplate reader with Fluorescence Polarization (Polar Star Optima, BMG Labtech) set up at ex. $485 \mathrm{~nm}$ and em. $530 \mathrm{~nm}$ was used. $\mathrm{H}_{2} \mathrm{O}_{2}(500 \mu \mathrm{M})$ and diethyl maleate (DEM, $5 \mathrm{mM}$ ) served as positive controls and DPBS as the negative control. A cell-free interference control was prepared and taken through all the experimental steps, except for probe pre-incubation. The ROS percentage was calculated with:

$$
\% \text { Fluorescence }=\frac{\text { sample fluorescence }}{\text { control fluorescence }} \times 100
$$

\section{Statistical Analysis}

Data were analyzed with GraphPad Prism software version 6. Figures show the standard error of the mean \pm SEM. Statistical significance $\left({ }^{*} \mathrm{p}<0.05,{ }^{* *} \mathrm{p}<0.01,{ }^{* * *} \mathrm{p}<0.001\right.$, $* * * * p<0.0001$ ) was assessed by One-way Anova or Twoway Anova with adjusted correction for multiple comparisons using Dunnett's test (not matching or pairing). All results are from at least three independent experiments unless stated otherwise in the figure legend. For experiments with human blood, each independent experiment was from a distinct healthy blood donor. When the guidelines did not provide an acceptable threshold for the test, the negative control was used as a baseline to determine a statistically significant difference with the tested samples, as recommended by ASTM F1903. ${ }^{21}$

\section{Results \\ Characterization of Modified $\mathrm{CH}$ $\left(\mathrm{DEAE}_{12}-\mathrm{CH}-\mathrm{PEG}-\mathrm{FA}_{2}\right)$}

To evaluate the effect of DEAE and PEG-FA insertion on the $\mathrm{CH}$ structure, we calculated the percentage of each chemical group attached on the polymer chain, and estimated the MW of the new synthesized derivative. A diagram representing the synthesis procedure is available in supplementary figure S1. The DDA of the original non-modified $\mathrm{CH}$ was determined by ${ }^{1} \mathrm{H}-\mathrm{NMR}$ at $97.4 \%$, with a MW of $270 \mathrm{kDa}$, as measured with GPC. The degree of substitution (DS) of the DEAE groups inserted in the $\mathrm{CH}$ was $12 \%$. The percentage of PEG-FA in the $\mathrm{CH}$ structure was $2.02 \%$, as measured with a nanophotometer at $\lambda 363 \mathrm{~nm}$. The theoretical value of the average molar mass $(\mathrm{MM})$ per $\mathrm{DEAE}_{12}$-CH-PEG-FA ${ }_{2}$ residue was determined by ${ }^{1} \mathrm{H}-\mathrm{NMR}$ and calculated as $243.7 \mathrm{~g} / \mathrm{mol}$, using the DDA, degree of acetylation (DA), and DS values. Final MW of this derivative, according to GPC, was 259 $\mathrm{kDa}$. Figure S2 shows GPC traces for the original and modified $\mathrm{CH}$. DEAE $12-\mathrm{CH}-\mathrm{PEG}-\mathrm{FA}_{2}$ polymer is partly soluble in water after long stirring periods. Once $\mathrm{HCl}$ is added to water in equimolar amounts to those of the amino groups, other solutions like DPBS pH 7.2 can be added to reach the desired final concentration, and the polymer remains soluble at neutral $\mathrm{pH}$. The final $\mathrm{pH}$ will be the one used in the solution to reach the concentration to be tested, in our case pH 7.2. LAL assay, carried out on different samples of the synthesis process, revealed that our DEAE ${ }_{12}$-CH-PEG-FA 2 was free of endotoxin contamination (endotoxin levels were not detectable or inferior to $0.1 \mathrm{EU} / \mathrm{mL}$ ). A representation of the $\mathrm{DEAE}_{12}$-CH-PEG$\mathrm{FA}_{2}$ chemical structure, its ${ }^{1} \mathrm{H}-\mathrm{NMR}$ spectrum and general properties are shown in Figure 1.

\section{Characterization of $\mathrm{DEAE}_{12}-\mathrm{CH}-\mathrm{PEG}-\mathrm{FA}_{2}$ /siRNA Nanoparticles in DPBS pH 7.2}

The electrophoresis assays were carried out to determine the ideal N/P ratio between $\mathrm{DEAE}_{12}-\mathrm{CH}-\mathrm{PEG}-\mathrm{FA}_{2}$ and siRNA to form nanoparticles and complex the payload. Therefore, we chose a N/P ratio of 15:1, as there was no siRNA release during the agarose gel migration, which reflects good complexation (Figure 2A). Size and zeta potential assays (Figure $2 \mathrm{~B}$ and $\mathrm{C}$ ) for a $\mathrm{N} / \mathrm{P}$ ratio of 


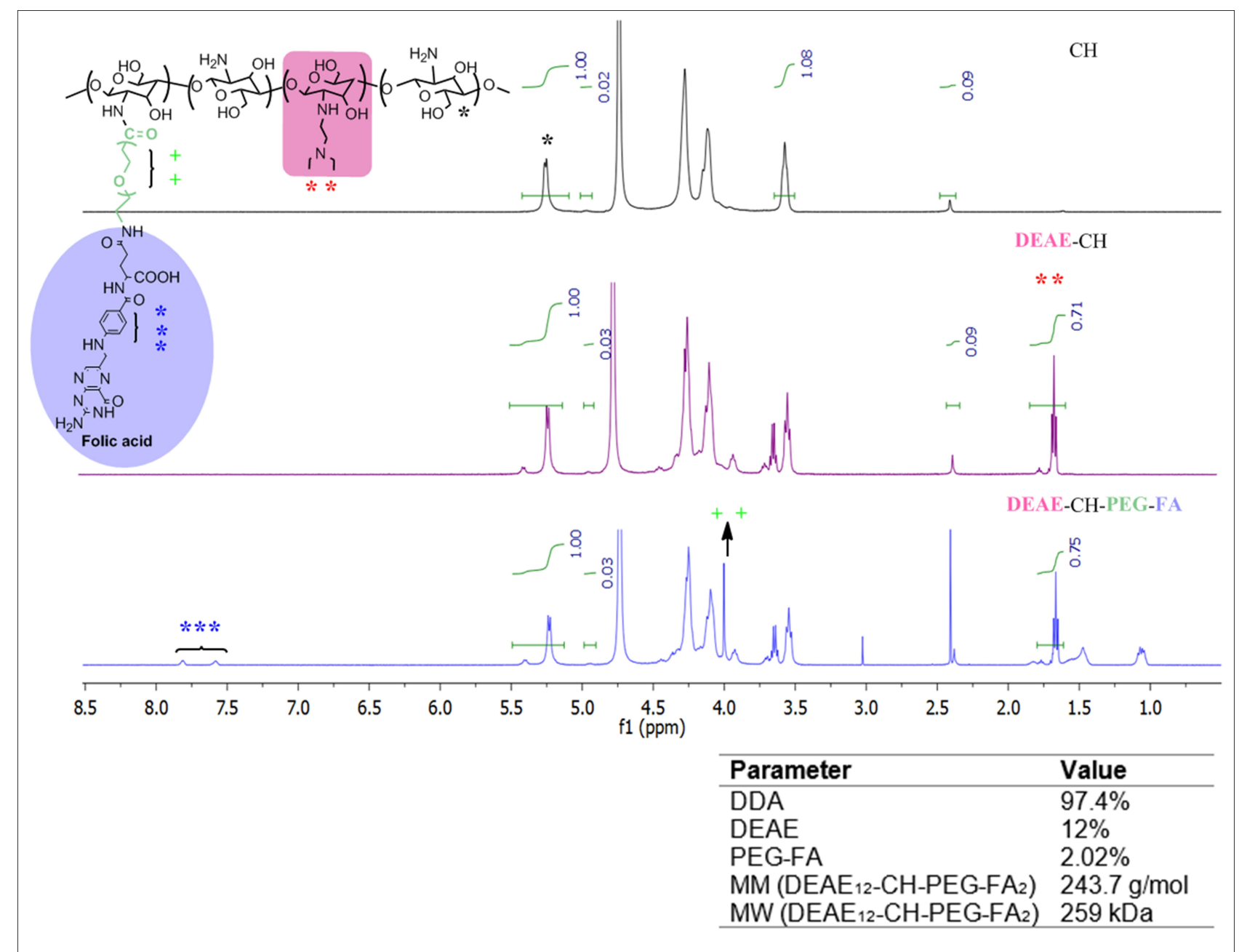

Figure I Chemical structure and characterization of DEAE $12-\mathrm{CH}-\mathrm{PEG}-\mathrm{FA}_{2}$ modified $\mathrm{CH}$. DEAE $\mathrm{I}_{12}-\mathrm{CH}-\mathrm{PEG}-\mathrm{FA} \mathrm{A}_{2}$ chemical structure (left-top). ' $\mathrm{H}-\mathrm{NMR}$ spectrum of deacetylated $\mathrm{CH}$ (right-top panel, DDA 97.4\%), DEAE $12-\mathrm{CH}$ (middle panel) and $\mathrm{DEAE}_{12}-\mathrm{CH}-\mathrm{PEG}-\mathrm{FA}_{2}$ (right-bottom panel). DEAE $12-\mathrm{CH}-\mathrm{PEG}-\mathrm{FA}_{2}$ properties (right-bottom).

15:1 showed nanoparticles of $208 \pm 33 \mathrm{~nm}$, with a polydispersity index (PDI) of $0.15 \pm 0.04$, and a charge of $+8.9 \pm 0.7 \mathrm{mV}$. Size vs time studies (Figure 2D and E) showed stable nanoparticles for a N/P ratio of $15: 1$, ranging from $194 \pm 10 \mathrm{~nm}$ (PDI $0.15 \pm 0.0$ ) at $\mathrm{t}=0$ to $224 \pm 6$ $\mathrm{nm}$ (PDI $0.18 \pm 0.02$ ) at $24 \mathrm{~h}$. Overall, this $24 \mathrm{~h}$ kinetic experiment showed good particle homogeneity from N/P ratios of 15:1 to 40:1 for all time points, with sizes $<235$ $\mathrm{nm}$ and PDI $<0.2$.

\section{Cell Viability and Toxicity}

The effect of $\mathrm{DEAE}_{12}-\mathrm{CH}-\mathrm{PEG}-\mathrm{FA}_{2} / \mathrm{siRNA}$ nanoparticles or free $\mathrm{DEAE}_{12}-\mathrm{CH}-\mathrm{PEG}-\mathrm{FA}_{2}$ on cell viability was tested using three types of cells and two assay methods. MTS determines cell viability and LDH release indicates a loss in membrane integrity, which is associated with cell death. ${ }^{32}$ Compared to Raw 264.7 cells and PBMC, MG-63 cells had the best viability and the lowest LDH release. For TPC, MG-63 cell viability was evaluated at $93.3 \pm 2.7 \%(\mathrm{p}<0.05)$ after $24 \mathrm{~h}$ of incubation and decreased to $76.0 \pm 5.1 \%(\mathrm{p}<0.01)$ after 48 $\mathrm{h}$ (Figure $3 \mathrm{~A}$ ). The LDH level varied from $1.8 \pm 0.5 \%$ to 5.4 $\pm 1.7 \%(\mathrm{p}<0.01)$ for the same time periods (Figure 3B). Although cell viability of Raw 264.7 macrophages was more affected at $10 \mathrm{x}$ and $5 \mathrm{x}$ concentrations (Figure $3 \mathrm{C}$ ), cell viability at TPC was still $78.3 \pm 4.7 \%(\mathrm{p}<0.05)$ and $71.8 \pm 3.0 \%(\mathrm{p}<0.0001)$ after 24 and $48 \mathrm{~h}$ of incubation, respectively. A dose-dependent response associated with time points was observed. $\mathrm{LDH}$ release was estimated at $45.9 \pm 5.8 \%(\mathrm{p}<0.0001)$ and $88.0 \pm 7.3 \%(\mathrm{p}<0.0001)$, following treatment for 24 and $48 \mathrm{~h}$ (Figure 3D). For its part, PBMC cell viability at TPC remained at $81.0 \pm 2.9 \%$ and $107.5 \pm$ $19.5 \%$ after 24 and $48 \mathrm{~h}$ of incubation, respectively (Figure 3E). LDH release reached $12.3 \pm 1.4 \%(\mathrm{p}<0.01)$ and $8.8 \pm 3.5 \%$ after 24 and $48 \mathrm{~h}$ post-exposure 

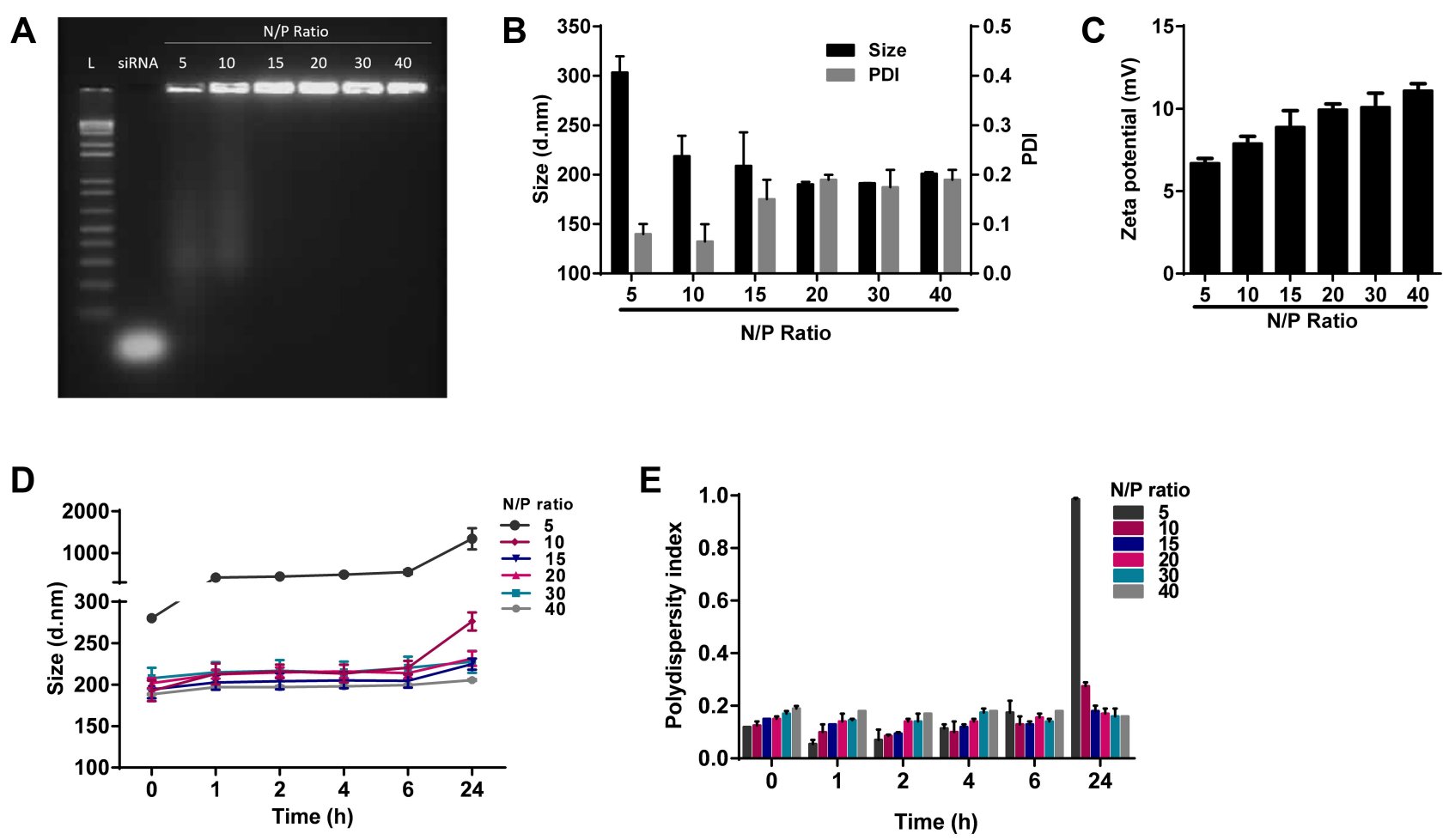

Figure 2 Characterization of DEAE 12 -CH-PEG-FA $/$ siRNA nanoparticles in DPBS pH 7.2. Nanoparticles had DEAE 12 -CH-PEG-FA $/$ siRNA N/P ratios of 5:I, 10:I, I5:I, 20:I, 30:I and 40:I. (A) Nanoparticles agarose electrophoresis using $0.5 \mu \mathrm{g}$ of siRNA/well. Lane I: ladder (I kb pairs); lane 2 free siRNA; lane 3-8: DEAE $12-\mathrm{CH}_{-}$PEG-FA $/ \mathrm{siRNA}^{2}$ nanoparticles at the indicated N/P ratios. (B) Nanoparticle size and PDI with $0.02 \mathrm{mM}$ of siRNA/optical-cell. (C) Zeta potential of nanoparticles at the indicated N/P ratios. (D) Nanoparticle size vs time and (E) their corresponding PDI. All values are expressed as the mean \pm SEM of two independent experiments.

(Figure 3F). The viability threshold for this test is $>70 \%$ according to ISO $10,993-5,{ }^{35}$ meaning that our nanoparticles still meet the criteria for MG-63 cells and PBMC. Even though the viability of Raw 264.7 macrophage cells was $>70 \%$ when evaluated by MTS assay, LDH release results showed a much higher mortality rate which does not reflect MTS data.

Free DEAE $12-\mathrm{CH}-\mathrm{PEG}-\mathrm{FA}_{2}$ showed similar cell viability for all cell types, at different incubation times and particle concentrations, as measured by the MTS assay and $\mathrm{LDH}$ release (Figure $\mathrm{S} 3 \mathrm{~A}-\mathrm{F}$ ).

\section{Hemocompatibility of Nanoparticles}

In order to define the hemotoxicity profile of our $\mathrm{DEAE}_{12-}$ CH-PEG-FA $2 /$ siRNA nanoparticles and free DEAE $12-\mathrm{CH}-$ PEG-FA 2 , a set of experiments were performed to evaluate the effect of their interaction with human blood components, namely cells, proteins and mediators. All tested nanoparticle and free $\mathrm{DEAE}_{12}-\mathrm{CH}-\mathrm{PEG}-\mathrm{FA}_{2}$ concentrations with hemolysis assay (Figure $4 \mathrm{~A}$ and $\underline{\mathrm{S}} 4 \mathrm{~A}$ ) were under the ASTM threshold of 5\%. ${ }^{36}$ A platelet aggregation test (Figure 4B) has shown that all concentrations (except for $10 \mathrm{x}$ ) meet the guideline threshold of $<20 \%$ for platelet clotting. TPC and $5 \mathrm{x}$ induced platelet clotting at $2.9 \pm$ $1.1 \%$ and $15.6 \pm 8.6 \%$, respectively, with no statistically significant difference compared to DPBS. For free DEAE $_{12}-\mathrm{CH}-\mathrm{PEG}-\mathrm{FA}_{2}$ (Figure S4B) aggregation was inferior to $20 \%$ for all concentrations, with a clot formation of $5.3 \pm 1.4 \%$ for TPC. The hemagglutination assay showed a weak agglutination with the formation of a smooth mat of red blood cells on the well bottom (Figure 4C) for all concentrations, except for 10x which showed a mild aggregation. Free $\mathrm{DEAE}_{12}-\mathrm{CH}-\mathrm{PEG}-\mathrm{FA}_{2}$ had similar outcomes as well (Figure S4C).

Plasma clotting times, measured with the APTT, PT and TT assays, showed that all DEAE $_{12}-\mathrm{CH}-\mathrm{PEG}-\mathrm{FA}_{2}$ /siRNA nanoparticle concentrations were within the normal clinical limits established for the test (Figure 4D). For TPC, the clotting times were as follows: $13.1 \pm 0.2 \mathrm{~s}$ for $\mathrm{PT}, 33.1 \pm 1.3 \mathrm{~s}$ for APTT and $15.6 \pm 0.4 \mathrm{~s}$ for TT; while for DPBS they were: $12.6 \pm 0.2 \mathrm{~s}$ for PT, $32.7 \pm 1.3 \mathrm{~s}$ for APTT and $15.8 \pm 0.4 \mathrm{~s}$ for $\mathrm{TT}$, with no statistically significant difference. Free DEAE $_{12}-\mathrm{CH}-\mathrm{PEG}-\mathrm{FA}_{2}$ showed similar responses (Figure S4D).

A Western blot analysis of the native $\mathrm{C} 3 \alpha$ chain cleavage $(\sim 115 \mathrm{kDa})$ to split product $\mathrm{C} 3 \mathrm{c}(\sim 43 \mathrm{kDa})$, evaluated the 

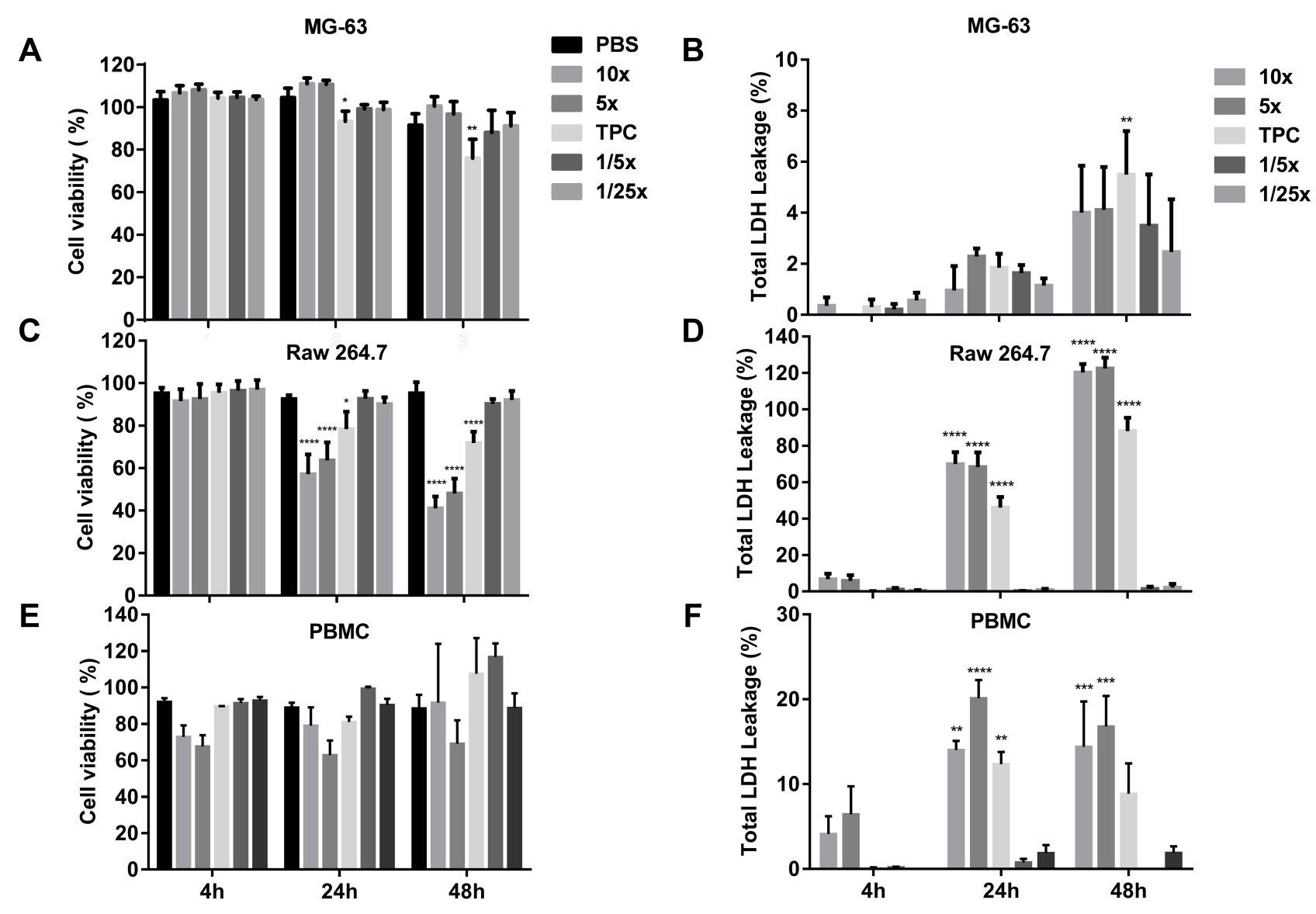

Figure 3 Cell viability and toxicity of DEAE ${ }_{12}-\mathrm{CH}-\mathrm{PEG}-\mathrm{FA}_{2} /$ siRNA nanoparticles. The cytotoxic effect of nanoparticles was evaluated using the MTS (A, C, E) and LDH assays (B, D, F) in MG-63 cells, Raw 264.7 macrophage cells and PBMC. Cells were incubated with samples for 4,24 and $48 \mathrm{~h}$ at $37^{\circ} \mathrm{C}$. After the exposure time, MTS and LDH tests were performed. DPBS was used as the negative control. $500 \mu \mathrm{M} \mathrm{H}_{2} \mathrm{O}_{2}$ and $1 \% \mathrm{v} / \mathrm{v}$ triton X-100 were used as positive controls for MTS and LDH assays, respectively. ${ }^{*} p<0.05,{ }^{*} p<0.01, * * * p<0.001$, $* * * * p<0.0001$ are significantly different from the negative control. Data are expressed as the mean \pm SEM of three independent experiments and were analyzed by Two-way ANOVA (post hoc Dunnett's test). Blood samples for PBMC were collected from three different healthy human donors. See Table I for DEAE $12-\mathrm{CH}-\mathrm{PEG}-\mathrm{FA}_{2}$ and siRNA concentrations.

activation of any of the three major pathways of the complement system (classical, alternative and lectin). Figure 4E shows that all nanocomplexes meet the guideline criteria, as none of the $\mathrm{DEAE}_{12}-\mathrm{CH}-\mathrm{PEG}-\mathrm{FA}_{2} / \mathrm{siRNA}$ nanoparticle concentrations led to complement system activation, as indicated by the absence of $\mathrm{C} 3 \mathrm{c}$ cleaved products, contrary to the positive control $(\mathrm{CVF})$. Free $\mathrm{DEAE}_{12}-\mathrm{CH}-\mathrm{PEG}-\mathrm{FA}_{2}$ showed the same effect as nanocomplexes (Figure S4E). Transferrin ( $\sim 77 \mathrm{kDa})$ was used as a serum loading control, showing equal protein content between samples.

\section{Nanoparticle Potential to Induce Cytokines}

A key test to estimate one of the possible immune responses to cell-particle interactions is to quantify the production of pro- and anti-inflammatory cytokines. In PBMC, no statistically significant differences in TNF- $\alpha$ (Figure $5 \mathrm{~A}$ ) and IL6 (Figure 5B) secretion were observed, in any of the
DEAE $_{12}-\mathrm{CH}-\mathrm{PEG}-\mathrm{FA}_{2} /$ siRNA nanoparticles or free DEAE $_{12}-\mathrm{CH}-\mathrm{PEG}-\mathrm{FA}_{2}$ concentrations tested when compared to DPBS. TNF- $\alpha$ expression levels at TPC were $287.8 \pm 67.0 \mathrm{pg} / \mathrm{mL}$ vs $84.5 \pm 44.5 \mathrm{pg} / \mathrm{mL}$ for DPBS, while for LPS they were $1117 \pm 185.2 \mathrm{pg} / \mathrm{mL}$. IL-6 levels reached $150.2 \pm 44.1 \mathrm{pg} / \mathrm{mL}$ for TPC vs $55 \pm 49.2 \mathrm{pg} / \mathrm{mL}$ for DPBS, and $927.8 \pm 117.1 \mathrm{pg} / \mathrm{mL}$ for LPS. On the other hand, IL-8 and IL-1 $\beta$ (Figure 5C and D) were both secreted in response to $\mathrm{DEAE}_{12}-\mathrm{CH}-\mathrm{PEG}-\mathrm{FA}_{2} / \mathrm{siRNA}$ nanoparticles. The former reached $4082 \pm 1313 \mathrm{pg} / \mathrm{mL}$ at TPC vs $418.3 \pm 200.0 \mathrm{pg} / \mathrm{mL}$ for DPBS and $7539 \pm 2079 \mathrm{pg} / \mathrm{mL}$ for LPS, while the latter reached $629.8 \pm 111.0 \mathrm{pg} / \mathrm{mL}$ for TPC vs $100.6 \pm 45.6 \mathrm{pg} / \mathrm{mL}$ for DPBS $(\mathrm{p}<0.01)$ and $502.8 \pm$ $148.3 \mathrm{pg} / \mathrm{mL}$ for LPS. Finally, IL-10 (Figure 5E) and IL-4 (Figure 5F) expression levels were not statistically significant compared to DPBS. Similar secretion profiles were observed when cells were incubated with free $\mathrm{DEAE}_{12^{-}}$ CH-PEG-FA 2 (Figure S5A-F). 


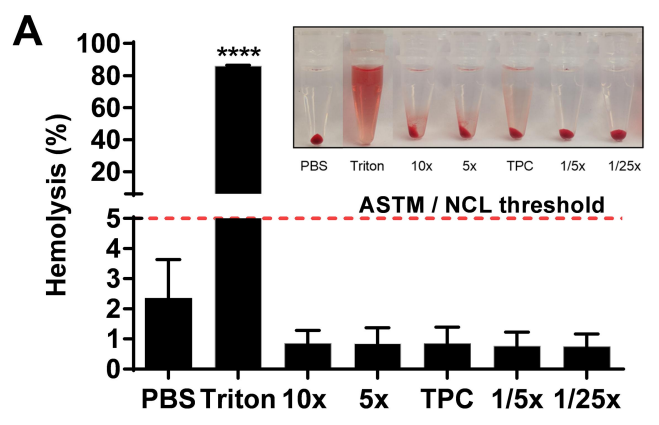

C Score
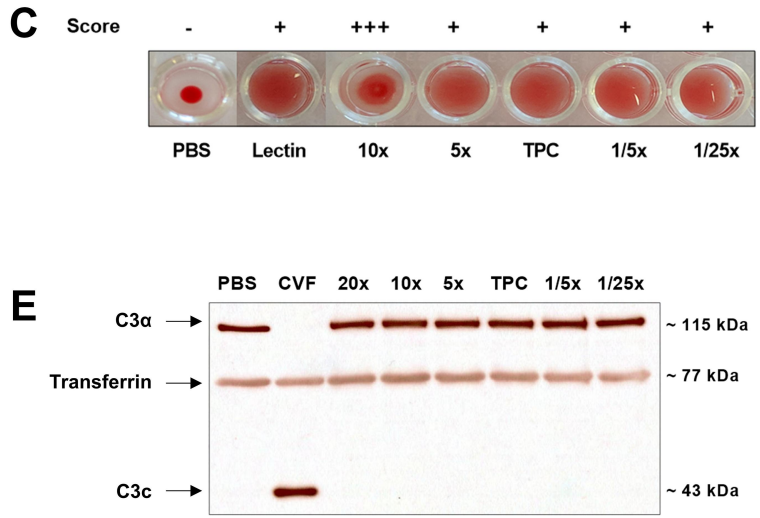

B

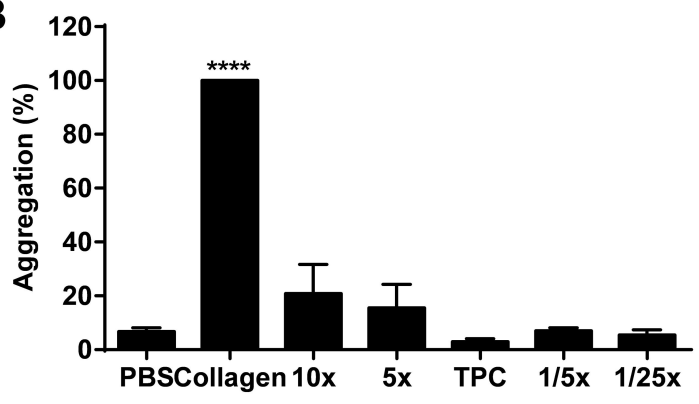

D

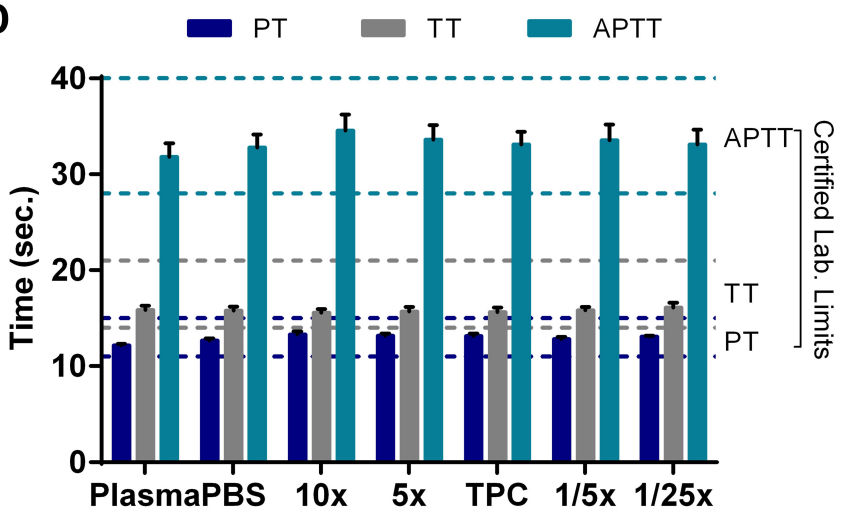

Figure 4 Hemocompatibility of DEAE ${ }_{12}-\mathrm{CH}-\mathrm{PEG}-\mathrm{FA}_{2} / \mathrm{siRNA}$ nanoparticles. (A) Hemolysis percentage induced by nanoparticles and visual inspection of tubes after the centrifugation step (inset). Human blood was incubated with samples for $3 \mathrm{~h}$ at $37^{\circ} \mathrm{C}$. DPBS and triton represent the negative and positive controls, respectively. Pink dash line shows the $5 \%$ threshold of ASTM from which a sample is considered to have hemolytic properties. Data are expressed as the mean \pm SEM of three independent experiments and were analyzed by One-way ANOVA (post hoc Dunnett's test). (B) Nanoparticle platelet aggregation profiles after platelet-rich plasma was incubated with samples for a 6 min run at $37^{\circ} \mathrm{C}$. PBS and collagen represent the negative and positive controls, respectively. Data are expressed as the mean \pm SEM of three independent experiments and were analyzed by One-way ANOVA (post hoc Dunnett's test). (C) Hemagglutination activity produced by nanoparticles in an erythrocyte suspension after I h of incubation at $37^{\circ} \mathrm{C}$. DPBS and lectin represent the negative and positive controls, respectively. Pictures represent one of three independent experiments with similar results. The agglutination analysis was performed as described in the methods. (D) Effect of particles on plasma coagulation times: prothrombin time (PT), thrombin time (TT) and activated partial thromboplastin time (APTT). Measures were taken after a 30 min incubation of human plasma with samples at $37^{\circ} \mathrm{C}$. The normal coagulation time limits are indicated with a colored dash line (PT II $\leq 15$ s (dark blue), TT I4 $\leq 21$ s (gray) and APTT $28 \leq 40$ s (light green)). Non-treated plasma and DPBS were used as internal controls for the test. Data are expressed as the mean \pm SEM of four independent experiments and were analyzed by Two-way ANOVA (post hoc Dunnett's test). (E) Complement activation assay showing the expression levels of a native $\mathrm{C} 3 \alpha$ chain $(\sim 115 \mathrm{kDa})$ and its cleavage product $\mathrm{C} 3 \mathrm{c}(\sim 43 \mathrm{kDa})$, after human plasma exposure to nanoparticles for $30 \mathrm{~min}$ at $37^{\circ} \mathrm{C}$. DPBS and CVF represent the negative and positive controls, respectively. Transferrin ( 77 kDa) was used as a serum loading control. Blots represent one of three independent experiments with similar results. For all experiments, blood samples were collected from at least three healthy human donors. **** $\mathrm{p}<0.000 \mathrm{I}$ are significantly different from the negative control. See Table I for DEAE $\mathrm{I}_{2}-\mathrm{CH}-\mathrm{PEG}-\mathrm{FA}_{2}$ and siRNA concentrations.

\section{NO and ROS Production}

Nanoparticles have the capacity to produce ROS and impair the normal intracellular redox homeostasis, overriding the antioxidant capacity of cells. ${ }^{17} \mathrm{NO}$ and ROS are effector molecules released by activated macrophages to defend the cell from pathogens. Therefore, the detection of ROS and NO can help estimate the effect of $\mathrm{DEAE}_{12}-\mathrm{CH}-$ $\mathrm{PEG} \mathrm{FA}_{2} / \mathrm{siRNA}$ nanoparticles or free $\mathrm{DEAE}_{12}$-CH-PEG$\mathrm{FA}_{2}$ on cell responses.

Our results on NO production showed no statistically significant difference for any of the tested particle concentrations, when compared to the negative control DPBS (Figure 6A). Similar results were found with free DEAE $_{12}$-CH-PEG-FA 2 (Figure S6A).

As for ROS, Figure 6B shows no statistically significant difference between samples and the negative control
DPBS. Conversely, there was an increase in ROS production for the $\mathrm{H}_{2} \mathrm{O}_{2}$ and DEM positive controls, from the start of exposure for the former, and $2 \mathrm{~h}$ after incubation for the latter. Free $\mathrm{DEAE}_{12}$-CH-PEG-FA 2 had a similar response for all tested concentrations (Figure S6B).

\section{Discussion}

In the last decades, $\mathrm{CH}$ has garnered significant interest because of its many applications in several biomedical fields, as well as for its physicochemical properties and biocompatibility. On the nanoscale, the therapeutic potential of this polysaccharide as a drug delivery system and as a vector of genetic payloads, among others, has been acknowledged. ${ }^{3}$ We have previously reported that adding DEAE to the main $\mathrm{CH}$ chain modifies its $\mathrm{pKa}$ characteristics, improving the buffering capacity of nanoparticles, 
A

C

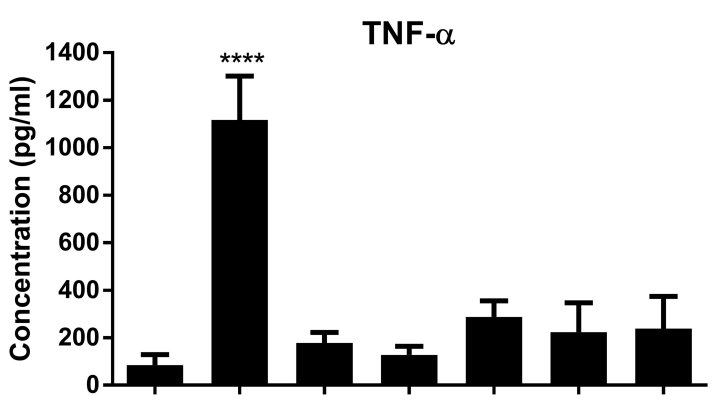

E
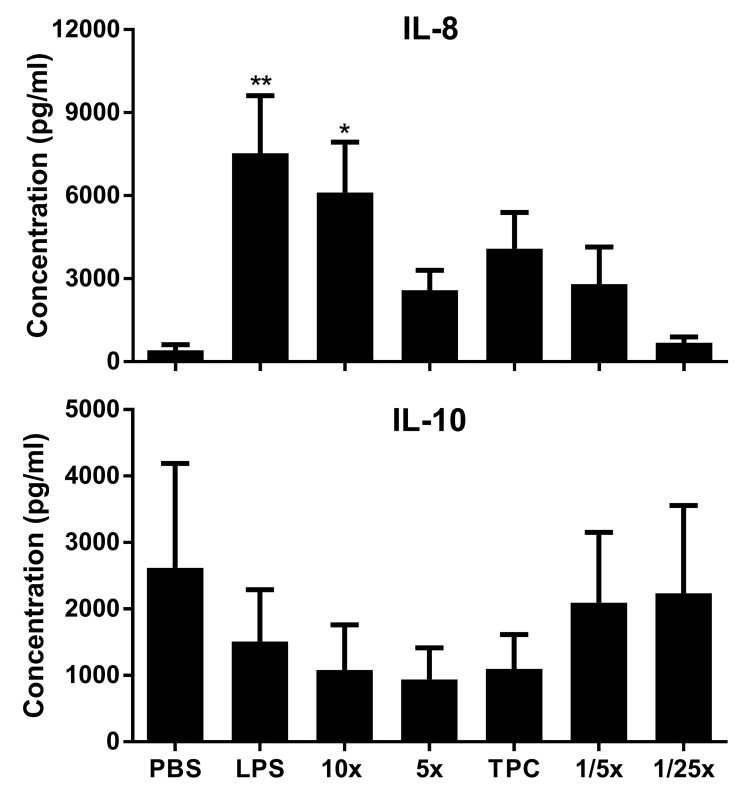

B

D

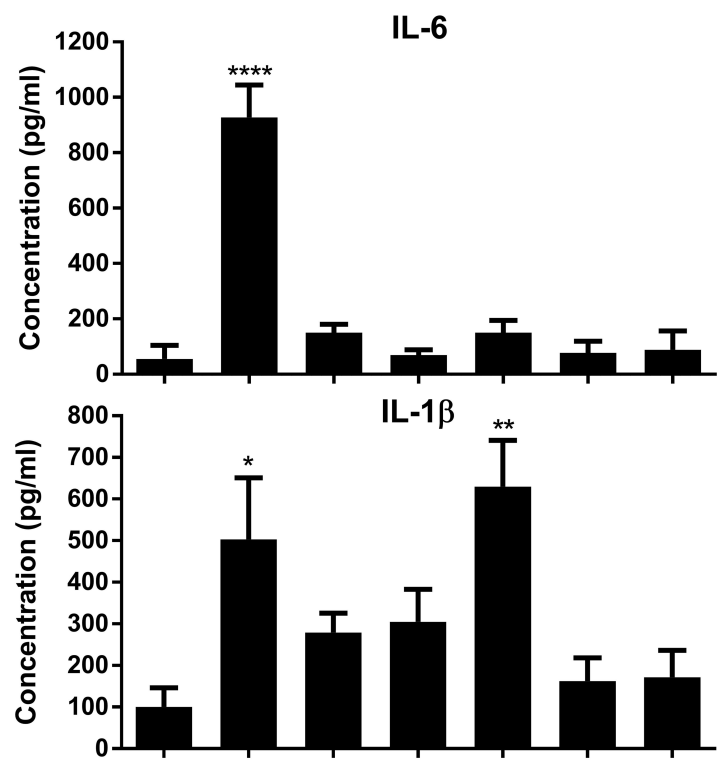

F

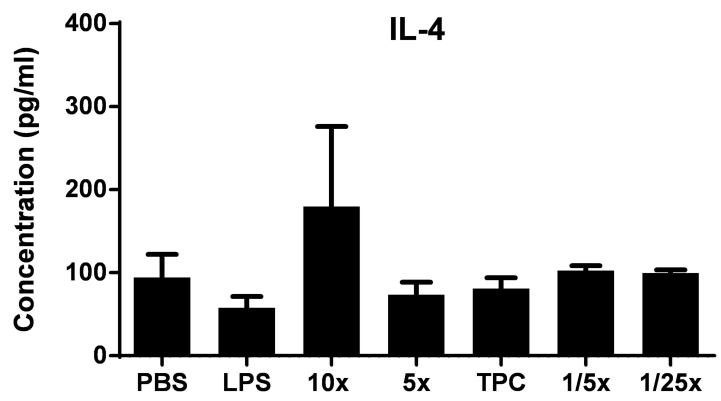

Figure 5 Nanoparticle potential to induce cytokines. (A) TNF- $\alpha$, (B) IL-6, (C) IL-8, (D) IL-I $\beta$, (E) IL-I0, and (F) IL-4 cytokines were detected by ELISA, after PBMC incubation with nanoparticles for $24 \mathrm{~h}$ at $37^{\circ} \mathrm{C}$. DPBS and LPS $(20 \mathrm{ng} / \mathrm{mL})$ were used as negative and positive controls, respectively. Data are expressed as the mean \pm SEM of five independent experiments, each one from a different healthy human donor, except for IL-4 where $\mathrm{N}=4$. ${ }^{*} \mathrm{p}<0.05, * * \mathrm{p}<0.0 \mathrm{I}$, $* * * * p<0.000 \mathrm{I}$ are significantly different from the negative control. Data were analyzed by One-way ANOVA (post hoc Dunnett's test). See Table I for DEAE $12-\mathrm{CH}_{-}-\mathrm{PEG}-\mathrm{FA}{ }_{2}$ and siRNA concentrations.

as well as their endosomal escape and the release of cargo in the cytoplasm, which enhances their transfection efficiency. ${ }^{19,26}$ As previously shown, adding FA to our nanovector also improves the capacity to target cells expressing the folate receptor (FR). ${ }^{28}$ Herein, we synthesized stable DEAE ${ }_{12}$-CH-PEG-FA $2 /$ siRNA nanoparticles $^{2}$ at physiological $\mathrm{pH}$ (7.2), as demonstrated by the uniformity in size and PDI measurements over $24 \mathrm{~h}$ at a N/P ratio of 15:1. This characteristic improves their potential for therapeutic applications as it makes their use in biological conditions possible. $\mathrm{CH}$ interacts electrostatically with genetic materials to form nanoparticles without the need for organic solvents, thanks to its positively charged surface. Therefore, a simple nanoparticle preparation in a DPBS solution ( $\mathrm{pH}$ 7.2) was favored, according to ASTM and NCL recommendations, as it prevents additives/surfactants toxicity. ${ }^{46,47}$

In our study, we followed the guidelines from ISO, ${ }^{48}$ $\mathrm{ASTM}^{49}$ and $\mathrm{NCL},{ }^{23}$ which were adapted to our intended route of exposure, potential cellular targets and equipment/ reagent availability. This allowed us to estimate the biological response to $\mathrm{CH}$ in two ways: complexed with siRNA and in free form. The protocols chosen evaluated the interaction between nanocomplexes and blood components, as our nanoparticles are intended to pass through the bloodstream before reaching their target. All the in vitro studies were performed with TPC as the principal concentration, derived from a potential therapeutic dose in an in vivo study. Moreover, we achieved a modified $\mathrm{CH}$ polymer synthesis with undetectable levels of endotoxin contamination $(<0.1 \mathrm{EU} / \mathrm{mL})$, to avoid interference with the in vitro outcomes.

In the present study, PBMC were studied for their potential cell-particle interactions in the bloodstream. PBMC (only monocytes) and Raw 264.7 cells express FR over their surface, ${ }^{50,51}$ which may be recognized by the folate ligand grafted to the $\mathrm{CH}$ structure. For their part, MG-63 cells were of interest as they do not express $\mathrm{FR},{ }^{28,52}$ making it possible to correlate the effect of folate 


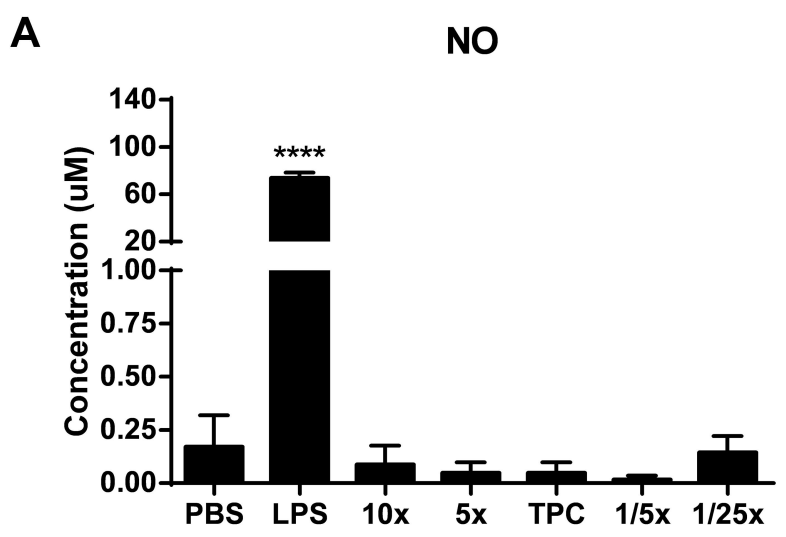

B

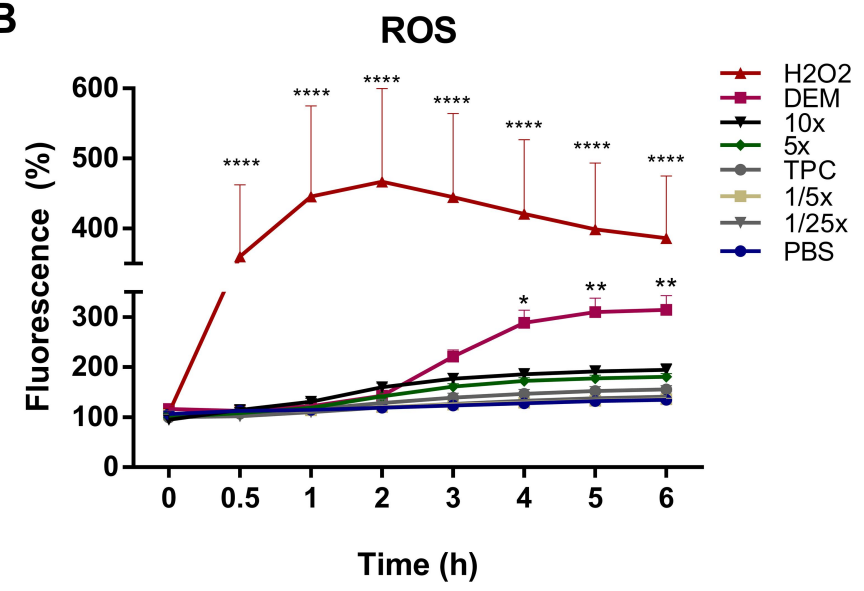

Figure 6 Nitric oxide (NO) and reactive oxygen species (ROS) production in response to nanoparticles. (A) NO concentration produced by Raw 264.7 macrophage cells in response to nanoparticles. Cells were incubated with samples for $48 \mathrm{~h}$ at $37^{\circ} \mathrm{C}$. $\mathrm{NO}_{2}{ }^{-}$concentration was measured in cell supernatants using the Greiss reagent. DPBS and LPS (100 ng/mL) were used as negative and positive controls, respectively. Data were analyzed by One-way ANOVA (post hoc Dunnett's test). (B) ROS induction by nanoparticles in Raw 264.7 cells. Cells were exposed to samples for 6 h, after pre-incubation with $20 \mu M$ of DCFH-DA probe. Fluorescence readings (ex. 485 nm and em. $530 \mathrm{~nm}$ ) were performed at the indicated time points. $500 \mu \mathrm{M} \mathrm{H}_{2} \mathrm{O}_{2}$ and $5 \mathrm{mM}$ DEM were used as positive controls. DPBS in blue represents the negative control. Data were analyzed by Two-way ANOVA (post hoc Dunnett's test). Data from NO and ROS are expressed as the mean \pm SEM of three independent experiments. * $<0.05$, $*^{* *}<<0.01, *^{* * *} \mathrm{p}<0.000 \mathrm{I}$ are significantly different from the negative control. See Table I for $\mathrm{DEAE} \mathrm{E}_{12}-\mathrm{CH}-\mathrm{PEG}-\mathrm{FA}{ }_{2}$ and siRNA concentrations.

targeting to the overall cell viability results. Cytotoxicity studies revealed that cell viability and $\mathrm{LDH}$ release were dose, time and cell-type dependent. As expected, both MG-63 and PBMC cell viability were not significantly affected at the three lowest concentration levels (TPC, 1/ $5 \mathrm{x}$ and $1 / 25 \mathrm{x}$ ) and for all incubation times (4, 24 and $48 \mathrm{~h}$ ). This suggests a low toxicity profile for our nanoparticles, which could be explained by the limited presence of FR on their surface. On the other hand, cell viability of Raw 264.7 macrophages decreased significantly in a dose and time-dependent manner. We hypothesize that the phagocytic role of these cells increases through the interaction between FR on the cell's surface and folic ligands conjugated to the $\mathrm{CH}$ structure, which may explain their reduced viability. This hypothesis is supported by Yang et $\mathrm{al}^{51}$ who report that folic acid on $\mathrm{CH}$ nanoparticles enhanced specific internalization and gene silencing in activated Raw 264.7 macrophages. Finally, the increasing level of LDH release from Raw 264.7 cells incubated with both $\mathrm{DEAE}_{12}-\mathrm{CH}-\mathrm{PEG}-\mathrm{FA}_{2} / \mathrm{siRNA}$ nanoparticles and free DEAE $_{12}-\mathrm{CH}-\mathrm{PEG}-\mathrm{FA}_{2}$ could be the result of a cell death process or a change in cell surface permeability. ${ }^{53}$ The discrepancy between MTS and LDH results in these cells could be explained by the transient formation of nanoscale holes on the cellular membrane during particle internalization, ${ }^{54,55}$ leading to $\mathrm{LDH}$ release ${ }^{56}$ in the culture medium. This could occur without it being correlated to cell death activation. Therefore, cell mitochondria could still process the MTS substrate and give acceptable viability results, as those obtained for Raw 264.7 cells, despite the high levels of LDH release observed. Different CH-based nanoparticles have been tested in Raw 264.7 macrophages and PBMC. Overall, cell viability is frequently above $70 \%$ when evaluated by MTS assay or its derivatives (MTT, XTT, etc.). ${ }^{57-61}$ For instance, Raw 264.7 cells treated with a mannosylated CH-graftpolyethylenimine copolymer showed $\sim 95 \%$ viability after a $24 \mathrm{~h}$ exposure at concentrations around our TPC. ${ }^{57}$ In PBMC, $\mathrm{CH}$ gold nanoparticles showed low cytotoxicity for concentrations up to $75 \mu \mathrm{M} .{ }^{60}$ However, most of the studies do not evaluate $\mathrm{LDH}$ release, making toxicity comparisons difficult, since the methodology used to evaluate cytotoxicity differs between research groups. Finally, it is clear that the $\mathrm{CH}$ nanoformulation, its physicochemical characteristics, tested concentrations, and percentage of cellular uptake, all contribute to the variations in cell viability results.

In the next step, hemocompatibility screening gave promising results for $\mathrm{DEAE}_{12}-\mathrm{CH}-\mathrm{PEG}-\mathrm{FA}_{2} / \mathrm{siRNA}$ nanoparticles when it came to blood-contact purposes. The interaction between erythrocyte and $\mathrm{DEAE}_{12}-\mathrm{CH}-\mathrm{PEG}-$

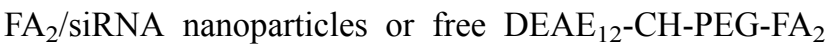
meet the ASTM threshold of $<5 \%$ for hemolytic properties. This weak hemolytic response can be attributed, in part, to the attachment of PEG molecules to the $\mathrm{CH}$ structure, which enhanced their hemocompatible properties. $^{62}$ Thereafter, we assessed plasma coagulation times and platelet aggregation properties, as data from the 
literature indicates that nanoparticles may trigger platelet adhesion or deplete coagulation factors, leading to thrombogenicity and bleeding. ${ }^{30,63}$ Our results showed that DEAE $_{12}-\mathrm{CH}-\mathrm{PEG}-\mathrm{FA}_{2} / \mathrm{siRNA}$ nanoparticles and free DEAE $_{12}-\mathrm{CH}-\mathrm{PEG}-\mathrm{FA}_{2}$ meet the established clinical limits for the test, as they did not influence any of the main coagulation pathways (intrinsic (APTT), extrinsic (PT) and common (TT)). Moreover, platelet aggregation satisfied the $<20 \%$ aggregation threshold for the four lowest nanocomplex concentrations (5x, TPC, 1/5x and 1/25x), establishing their low platelet clotting properties. Finally, the results from the complement activation test also fulfill the guideline requirements as nanoparticles were unable to cleave the $\mathrm{C} 3 \alpha$ chain molecule. This is an important characteristic to avoid allergic and anaphylactic reactions ${ }^{63}$ when aiming for systemic administration.

However, the hemagglutination assay showed a slight aggregation of red blood cells at all concentrations of $\mathrm{DEAE}_{12}-\mathrm{CH}-\mathrm{PEG}-\mathrm{FA}_{2} / \mathrm{siRNA}$ nanoparticles or free DEAE $_{12}-\mathrm{CH}-\mathrm{PEG}-\mathrm{FA}_{2}$. This weak cell adhesion occurred without loss of membrane integrity, as the low hemoglobin release in the hemolysis test showed. Lima et al, ${ }^{38}$ found that the contact between $\mathrm{CH}$ nanoparticles and erythrocytes creates a net that could trigger hemagglutination. The polymer's positive charge could explain this, as it may allow an electrostatic interaction with the negative surface of red blood cells, and activate the agglutination process. ${ }^{38}$ This hypothesis is supported by the findings of Fan et al, ${ }^{64}$ who confirmed that $\mathrm{CH}$ nanoparticles can easily attach to erythrocyte membranes. Our nanoparticles showed a zeta potential of $+8.9 \pm$ $0.7 \mathrm{mV}$ (N/P ratio of $15: 1$ ), which is considered a neutral surface charge according to NCL Method PCC-2. ${ }^{65}$ However, it should be noted that the erythrocytes were resuspended in a $\mathrm{NaCl}$ solution ( $\mathrm{pH}$ 5.5), as recommended in the hemagglutination protocol. Thus, we assume that a decrease in $\mathrm{pH}$ may have protonated the $\mathrm{CH}$ amine groups and raised the density of the positive charge, increasing its interaction with red blood cells. Hence, the characterization of nanocomplexes with the same medium used for in vitro assays is appropriate. Unfortunately, it was not possible to exactly reproduce the testing conditions for a DLS measure, as interference made it impossible to detect an acceptable reading. Interestingly, current hemagglutination assays still lack a validated quantitative and predictive technique. However, the search for alternative methods is beyond the framework of this study.

We also analyzed the ability of nanoparticles to modulate cytokine expression, namely TNF- $\alpha$, IL-1 $\beta$, IL-6, IL-8, IL-4 and IL-10, as they play a key role in the inflammatory regulation processes. ${ }^{66}$ Overall, most of the cytokine expression levels were not affected by our nanoparticles, although IL-8 and IL-1 $\beta$ were induced at some concentrations. Cytokines, such as TNF- $\alpha$, IL-1 $\beta$ and IL-6, have a significant function in the acute inflammatory process, causing swelling and redness. ${ }^{67}$ This response is increased when neutrophils are enrolled and activated, led by IL-8 chemokine. ${ }^{67}$ It is interesting to see that only the IL-1 $\beta$ and IL-8 levels were significantly released in our study, whereas TNF- $\alpha$ and IL- 6 remained unaltered. It is also important to note that IL-8 induction was only statistically significant for the highest concentration tested, which was intended to achieve some toxicological response. TNF- $\alpha$ and IL-1 $\beta$ are the primary cytokines that trigger and maintain inflammatory responses. ${ }^{68}$ The fact that IL-1 $\beta$ was induced but TNF- $\alpha$ was not seems to reflect an incomplete activation of the inflammatory pathway by $\mathrm{DEAE}_{12}-\mathrm{CH}-\mathrm{PEG}-\mathrm{FA}_{2} / \mathrm{siRNA}$ nanoparticles. This hypothesis is supported by the normal levels of IL-10 induced by our nanocomplexes, as this cytokine is substantially secreted during an inflammatory response to counterbalance the effects of pro-inflammatory mediators. ${ }^{69}$ Similarly to IL-10, IL-4 secretion was comparable to baseline. As IL-4 is a mediator involved in $\operatorname{IgE}$ induction $^{68}$ throughout an allergic reaction, its normal levels let us surmise that our $\mathrm{CH}$ is safe (as a derivative of shrimps' exoskeleton) from a hypersensitivity response.

IL- $1 \beta$ and IL- 6 are known to cause fever and are therefore useful as pyrogenic markers when testing pharmaceutical preparations. ${ }^{30}$ The fact that the LAL assay had a negative outcome, and IL-6 expression levels were low, allowed us to confirm that our $\mathrm{CH}$ nanoformulation is free of endotoxin contamination. High expression levels of IL-1 $\beta$ have been associated to CH's capacity to activate the NLRP3 inflammasome pathway in human PBMC, mouse peritoneal macrophages and mouse bone marrow-derived macrophages (BMM $).{ }^{70}$ BMMФ cells released a significant level of IL$1 \beta$ in response to $\mathrm{CH}$ without secretion of other proinflammatory cytokines, such as TNF- $\alpha$ and IL-6, supporting our results. ${ }^{70}$ Similarly, Feng et al $^{71}$ have reported an IL-1 $\beta$ production by Raw 264.7 macrophage cells, after stimulation with oligochitosans, which may be related to the recognition of this molecule by mannose receptors on the cell's surface. There are three main theories regarding the activation of the inflammasome pathway: the production of ROS, the destabilization of lysosomes during particle escapement, and the $\mathrm{K}^{+}$efflux. ${ }^{70}$ According to our results, neither DEAE ${ }_{12}-\mathrm{CH}-$ $\mathrm{PEG}_{-\mathrm{FA}_{2}} / \mathrm{siRNA}$ nanoparticles nor free $\mathrm{DEAE}_{12}-\mathrm{CH}-\mathrm{PEG}-$ 
$\mathrm{FA}_{2}$ produced ROS, which suggests that inflammasome activation is not caused by ROS in this study. With regard to the lysosome translocation theory, we speculate that during nanoparticle escape from these organelles the inflammasome system could be activated, which may explain the production of IL-1 $\beta$. In turn, IL-1 $\beta$, as a mediator of the acute response, may have an effect on immune cells to produce IL-8. CH has been recognized as an immunostimulatory agent, ${ }^{72}$ as an adjuvant in vaccines, ${ }^{73}$ and as a polymer with antiinflammatory properties. ${ }^{74}$ This last characteristic could set it apart from other polymers with a history of more consistent inflammatory reactions, such as PEI, ${ }^{67}$ where intracellular stress and apoptotic cell death processes are involved. ${ }^{75}$ In any case, deeper mechanistic studies about the inflammasome pathways and other $\mathrm{CH}$ signaling pathways are needed, to improve our understanding of the processes involved in the cellular response to $\mathrm{CH}$.

Finally, oxidative stress studies showed that neither DEAE $_{12}$-CH-PEG-FA $2 /$ siRNA nanoparticles nor free DEAE $_{12}$-CH-PEG-FA 2 induced ROS or NO production by Raw 264.7 macrophage cells. These outcomes are interesting as nanoparticle-induced oxidative stress is involved in inflammatory response, cytotoxicity and genotoxicity. ${ }^{76} \mathrm{CH}$ has been associated with antioxidant activity thanks to its ROS scavenging ability. ${ }^{77}$ For instance, $\mathrm{CH}$ has shown antioxidative properties in a LPS-injected mouse model via the restoration of glutathione levels and catalase activity. ${ }^{78}$ Other $\mathrm{CH}$ modifications, such as gallic acid grafted onto O-carboxymethyl CH (GA-g-CMCS), showed a protective action against hydrogen peroxide treated cells, reducing ROS production and restoring superoxide dismutase, catalase and glutathione peroxidase activity. ${ }^{79}$ Also noteworthy is the literature data showing the capacity of $\mathrm{CH}$ to produce $\mathrm{ROS}$ and consequently oxidative stress. Jesus et $\mathrm{al}^{80}$ found that ROS production in Raw 264.7 macrophage cells was associated with the \%DDA of their $\mathrm{CH}$ polymer. Thus an $80 \%$ DDA in $\mathrm{CH}$ nanoparticles and polymer were able to induce ROS in a concentration-dependent manner, while a $93 \%$ DDA did not. Moreover, Sarangapani et $\mathrm{al}^{81}$ found that with a particular size of positively charged $\mathrm{CH}$ nanoparticles, the oxidative stress mechanism can be triggered through ROS generation and the depletion of glutathione, becoming selectively cytotoxic for leukemia cells. Similarly, Martinez et $\mathrm{al}^{60}$ proposed $\mathrm{CH}$ gold nanoparticles $(\mathrm{CH}-$ AuNPs) to induce ROS production as a possible treatment for cancer cells. Reactive nitrogen species (RNS) production by phagocytes, especially NO, are key molecules to measure nanoparticle-induced injury, ${ }^{76}$ and results reported in the literature are contradictory as for ROS. Thus, some $\mathrm{CH}$ formulations have the ability to induce NO production as part of the oxidative stress response, ${ }^{59}$ while others have no effect. ${ }^{80}$ It was also reported that $\mathrm{CH}$ possesses the ability to reduce the LPS-induced NO levels by Raw 264.7 macrophages. ${ }^{80,82}$ This conflicting data can be explained by the preparation procedures of the $\mathrm{CH}$ samples and their physicochemical characteristics, such as composition, size, charge and surface reactivity. ${ }^{76}$

Taking into consideration the general results from all assays, and the fact that DPBS outcomes are comparable to those of non-treated cells, we concluded that this particle suspension medium did not influence the data. Therefore, as DEAE 12 -CH-PEG-FA $2 /$ siRNA nanoparticles and free $\mathrm{DEAE}_{12}-\mathrm{CH}-\mathrm{PEG}-\mathrm{FA}_{2}$ had similar biological responses, we deduced that $\mathrm{CH}$ is the component with the strongest effect in the nanoformulation. This study allowed us to evaluate in vitro, the potential biological response to an in vivo dose of $30 \mu \mathrm{g}$ siRNA-SSB/mouse $(1.5 \mathrm{mg} / \mathrm{kg})$ complexed with $320 \mu \mathrm{g}$ of DEAE ${ }_{12}$-CH-PEG$\mathrm{FA}_{2} /$ dose. As in vitro assays may predict the toxicity of in vivo studies, ${ }^{30}$ a dose ranging between TPC and $1 / 5 \mathrm{x}$ concentration will be considered for the animal model.

This basic toxicological screening provides a strong starting point to evaluate the safety profile of nanomaterials (see Table 2). New complementary standard guidelines addressing nanotoxicology are available in several $\mathrm{FDA}^{83,84}$ and $\mathrm{ISO}^{85}$ reports. Guideline implementation makes it possible to compare outcomes from different studies across laboratories, as the experimental conditions are already established by the different organizations. Finally, relevant aspects, such as endotoxin contamination and nanoparticle characterization, have to be addressed early on, at the preclinical development stage, to avoid inconsistencies with in vitro results, to improve our interpretation and to correlate biological responses.

\section{Conclusion}

This study supports the application of endotoxin-free $\mathrm{DEAE}_{12}$ -CH-PEG-FA $2 /$ siRNA nanoparticles for potential bloodcontact purposes, thanks to their low hemotoxicity. This is illustrated by their weak hemolytic and platelet aggregation properties, and the absence of effect on complement system and coagulation times. Their size, siRNA complexation and stability over time are suitable for various applications. We observed that cytotoxicity is related to dose, cell type and exposure times. Moreover, their low oxidative stress response and cytokine production make them a promising candidate for 
Table 2 Toxicological Screening Guidelines

\begin{tabular}{|l|l|l|}
\hline Test & Protocol & Reference \\
\hline $\begin{array}{l}\text { Endotoxin } \\
\text { contamination }\end{array}$ & LAL assay & NCL method STE-I. ${ }^{29}$ \\
\hline \multirow{4}{*}{ Cytotoxicity } & MTS & ASTM E2526-08 ${ }^{32}$ and NCL \\
\cline { 2 - 3 } & GTA-2 ${ }^{33}$
\end{tabular}

Abbreviations: LAL, limulus amebocyte lysate; MTS, 3-(4,5-dimethylthiazol-2-yl)5-(3-carboxymethoxyphenyl)-2-(4-sulfophenyl)-2H-tetrazolium; $\mathrm{LDH}$, lactate dehydrogenase; ROS, reactive oxygen species; NCL, Nanotechnology Characterization Laboratory; ASTM, American Society for Testing and Materials.

gene therapy applications, especially in inflammatory conditions, warranting further investigation. Complementary studies will be carried out to clarify the mechanisms involved in LDH release and the IL-1 $\beta$ levels observed in our study. Based on its toxicological profile reported herein, we conclude that this $\mathrm{DEAE}_{12}-\mathrm{CH}-\mathrm{PEG}-\mathrm{FA}_{2} / \mathrm{siRNA}$ platform is safe for potential biomedical applications administered intravenously, orally or topically. Future trials of our nanoparticles will address the biodistribution and toxicity of particles in a mouse model, using an in vivo imaging system as well as monitoring of the biomarkers for organ function.

\section{Abbreviations}

APTT, activated partial thromboplastin time; ASTM, American Society for Testing and Materials; AUC, area under the curve; $B M M \Phi$, mouse bone marrow-derived macrophages; $\mathrm{CH}$, chitosan; $\mathrm{CVF}$, cobra venom factor; DA, degree of acetylation; DDA, degree of deacetylation; DEAE, diethylaminoethyl; DEM, diethyl maleate; DPBS, Dulbecco's phosphate-buffered saline; DS, degree of substitution; FA, folic acid; FDA, Food and Drug
Administration; FR, folate receptors; GPC, permeation chromatography; H2O2, hydrogen peroxide; HBSS, Hanks' balanced salt solution; H-NMR, nuclear magnetic resonance; IL, interleukin; ISO, International Organization for Standardization; LAL, limulus amebocyte lysate; LDH, lactate dehydrogenase; LPS, lipopolysaccharides; MM, molar mass; MTS, 3-(4,5-dimethylthiazol-2-yl)-5-(3-carboxymethoxyphenyl)-2-(4-sulfophenyl)-2H-tetrazolium; MW, molecular weight; N/P, amino groups/phosphate groups; NCL, Nanotechnology Characterization Laboratory; NiTi, nickel-titanium; NO, nitric oxide; OECD, Organization for Economic Cooperation and Development; PBMC, peripheral blood mononuclear cells; PEG, polyethylene glycol; PEI, polyethylenimine; PFH, plasma-free hemoglobin; PPP, platelet poor plasma; PRP, platelet-rich plasma; PT, prothrombin time; ROS, reactive oxygen species; SEM, standard error of the mean; siRNA, small interfering RNA; TBH, total blood hemoglobin; TNF- $\alpha$, tumor necrosis factor alpha; TPC, theoretical plasma concentration; TT, thrombin time.

\section{Data Sharing Statement}

Supporting data are available from authors.

\section{Ethics Approval and Informed Consent}

Experiments with human blood were approved by the Research Ethics Committee from Hôpital du Sacré-Cœur de Montréal (Protocol \# 2017-1462). Informed consent was obtained from healthy donor volunteers who were not ill nor under medication at the time of blood sample collection.

\section{Acknowledgment}

This work was done in Montréal (QC, Canada) and Sao Jose do Rio Preto (SP, Brazil).

\section{Author Contributions}

All authors made substantial contributions to conception and design, acquisition of data, or analysis and interpretation of data; took part in drafting the article or revising it critically for important intellectual content; gave final approval of the version to be published; and agree to be accountable for all aspects of the work.

\section{Funding}

This work was supported by grants from the « Ministère de l'Économie, de la Science et de l'Innovation du 
Québec, PSR-SIIRI-960» and the " Chaire de Recherche en Orthopédie de l'Université de Montréal à l'Hôpital du Sacré-Cour de Montréal » (J Fernandes and $\mathrm{M}$ Benderdour). Marcio Tiera was supported from FAPESP (Brazil) grants 2017/10331-5 and 2017/04392-1. Elsa Patricia Rondon, Houda Benabdoun and Francis Vallières held scholarships from the "Fonds de Recherche du Québec - Santé (FRQS) », and Maicon Petronio had a scholarship from FAPESP (Brazil) 2015/ 05148-1.

\section{Disclosure}

The authors report grants from Ministère de l'Économie, de la Science et de l'Innovation du Québec, the Chaire de Recherche en Orthopédie de l'Université de Montréal à l'Hôpital du Sacré-Coeur de Montréal, the Centre de Recherche of Hôpital du Sacré-Coeur de Montréal (Canada) and FAPESP (Brazil) during the conduct of the study. Elsa Patricia Rondon, Houda Abir Benabdoun and Francis Vallières report scholarships from the Fonds de Recherche du Québec - Santé (FRQS). Maicon Segalla Petronio reports scholarship from FAPESP (Brazil). The authors report no other potential conflicts of interest in this work.

\section{References}

1. Bobo D, Robinson KJ, Islam J, Thurecht KJ, Corrie SR. Nanoparticlebased medicines: a review of FDA-approved materials and clinical trials to date. Pharm Res. 2016;33(10):2373-2387. doi:10.1007/ s11095-016-1958-5

2. Shi Q, Rondon-Cavanzo E-P, Dalla Picola IP, et al. In vivo therapeutic efficacy of TNF $\alpha$ silencing by folate-PEG-chitosan-DEAE/siRNA nanoparticles in arthritic mice. Int $J$ Nanomed. 2018;13:387-402. doi:10.2147/IJN.S146942

3. Shi Q, Tiera MJ, Zhang X, Dai K, Benderdour M, Fernandes JC. Chitosan-DNA/siRNA nanoparticles for gene therapy. IntechOpen Limited ed. London, UK. In: Yuan X, editor. Non-Viral Gene Therapy. 19. 2011:455-480

4. Muxika A, Etxabide A, Uranga J, Guerrero P, De La Caba K. Chitosan as a bioactive polymer: processing, properties and applications. Int J Biol Macromol. 2017;105:1358-1368. doi:10.1016/j.ijbiomac. 2017.07.087

5. Abdelhamid HN, El-Bery HM, Metwally AA, Elshazly M, Hathout RM. Synthesis of CdS-modified chitosan quantum dots for the drug delivery of Sesamol. Carbohydr Polym. 2019;214:90-99. doi:10.1016/j.carbpol.2019.03.024

6. Zhao D, Yu S, Sun B, Gao S, Guo S, Zhao K. Biomedical applications of chitosan and its derivative nanoparticles. Polymers. 2018;10(4):462. doi:10.3390/polym 10040462

7. Mohebbi S, Nezhad MN, Zarrintaj P, et al. Chitosan in biomedical engineering: a critical review. Curr Stem Cell Res Ther. 2019;14 (2):93-116. doi:10.2174/1574888X13666180912142028

8. Dowaidar M, Nasser Abdelhamid H, Hällbrink M, Langel Ü, Zou X. Chitosan enhances gene delivery of oligonucleotide complexes with magnetic nanoparticles-cell-penetrating peptide. J Biomater Appl. 2018;33(3):392-401. doi:10.1177/0885328218796623
9. Guo X, Sun T, Zhong R, et al. Effects of chitosan oligosaccharides on human blood components. Front Pharmacol. 2018;9:1412. doi:10.3389/fphar.2018.01412

10. Dash BC, Réthoré G, Monaghan M, Fitzgerald K, Gallagher W, Pandit A. The influence of size and charge of chitosan/polyglutamic acid hollow spheres on cellular internalization, viability and blood compatibility. Biomaterials. 2010;31(32):8188-8197. doi:10.1016/j. biomaterials.2010.07.067

11. Shelma R, Sharma CP. Development of lauroyl sulfated chitosan for enhancing hemocompatibility of chitosan. Colloids Surf B Biointerfaces. 2011;84(2):561-570. doi:10.1016/j. colsurfb.2011.02.018

12. Mohammadi F, Golafshan N, Kharaziha M, Ashrafi A. Chitosanheparin nanoparticle coating on anodized NiTi for improvement of blood compatibility and biocompatibility. Int $J$ Biol Macromol. 2019;127:159-168. doi:10.1016/j.ijbiomac.2019.01.026

13. Pereira P, Pedrosa SS, Correia A, et al. Biocompatibility of a self-assembled glycol chitosan nanogel. Toxicol in Vitro. 2015;29 (3):638-646. doi:10.1016/j.tiv.2014.11.004

14. Magalhães PO, Lopes AM, Mazzola PG, Rangel-Yagui C, Penna T, Pessoa JA. Methods of endotoxin removal from biological preparations: a review. J Pharm Pharm Sci. 2007;10(3):388-404.

15. Halamoda-Kenzaoui B, Holzwarth U, Roebben G, Bogni A, BremerHoffmann S. Mapping of the available standards against the regulatory needs for nanomedicines. Wiley Interdiscip Rev Nanomed Nanobiotechnol. 2019;11(1):e1531. doi:10.1002/wnan.1531

16. Urbán P, Liptrott NJ, Bremer S. Overview of the blood compatibility of nanomedicines: A trend analysis of in vitro and in vivo studies. Wiley Interdiscip Rev Nanomed Nanobiotechnol. 2019;11(3):e1546. doi:10.1002/wnan.1546

17. ISO/TR 16197:2014(E). Nanotechnologies compilation and description of toxicological screening methods for manufactured nanomaterials. Available from: www.iso.org. Accessed July 24, 2020.

18. Locascio L, Reipa V, Zook J, Pleus R. Nanomaterial toxicity: emerging standards and efforts to support standards development. In: Murashov V, Howard J, editors. Nanotechnology Standards. Springer Science \& Business Media; 2011:179-208.

19. de Souza RHFV, Dalla Picola IP, Shi Q, et al. Diethylaminoethylchitosan as an efficient carrier for siRNA delivery: improving the condensation process and the nanoparticles properties. Int $J$ Biol Macromol. 2018;119:186-197. doi:10.1016/j.ijbiomac.2018.07.072

20. EN ISO 10993-4:2009. Biological evaluation of medical devices part 4: selection of tests for interactions with blood. Available from: www. iso.org. Accessed July 24, 2020.

21. ASTM F1903-10. Standard practice for testing for biological responses to particles in vitro. West Conshohocken, PA:ASTM International; 2010. DOI: 10.1520/F1903-10.

22. American Society for Testing and Materials [homepage on the Internet]. E56.03 environment, health, and safety. Available from: https://www.astm.org/COMMIT/SUBCOMMIT/E5603.htm. Accessed January 20, 2018.

23. Nanotechnology Characterization Laboratory [homepage on the Internet]. Assay cascade protocols. Available from: https://ncl.cancer. gov/resources/assay-cascade-protocols. Accessed January 20, 2018.

24. Abrams MT, Koser ML, Seitzer J, et al. Evaluation of efficacy, biodistribution, and inflammation for a potent siRNA nanoparticle: effect of dexamethasone co-treatment. Mol Ther. 2010;18 (1):171-180. doi:10.1038/mt.2009.208

25. Seitzer J, Zhang H, Koser M, Pei Y, Abrams M. Effect of biological matrix and sample preparation on qPCR quantitation of siRNA drugs in animal tissues. $J$ Pharmacol Toxicol Methods. 2011;63 (2):168-173. doi:10.1016/j.vascn.2010.09.005

26. Oliveira F, Dalla Picola IP, Shi Q, et al. Synthesis and evaluation of diethylethylamine-chitosan for gene delivery: composition effects on the in vitro transfection efficiency. Nanotechnology. 2013;24 (5):055101. doi:10.1088/0957-4484/24/5/055101 
27. Cho KC, Jeong JH, Chung HJ, Joe CO, Kim SW, Park TG. Folate receptor-mediated intracellular delivery of recombinant caspase-3 for inducing apoptosis. $J$ Control Release. 2005;108(1):121-131. doi:10.1016/j.jconrel.2005.07.015

28. Fernandes JC, Qiu X, Winnik FM, et al. Low molecular weight chitosan conjugated with folate for siRNA delivery in vitro: optimization studies. Int J Nanomed. 2012;7:5833-5845. doi:10.2147/IJN.S35567

29. Nanotechnology Characterization Laboratory [homepage on the Internet]. Neun BW, Ilinskaya AN, Dobrovolskaia MA. NCL method STE-1.1 detection and quantification of gram negative bacterial endotoxin contamination in nanoparticle formulations by end point chromogenic LAL assay. Version 1.3. Available from: https://ncl.cancer.gov/ resources/assay-cascade-protocols. Accessed January 20, $2018 .$.

30. Dobrovolskaia MA, McNeil SE. Understanding the correlation between in vitro and in vivo immunotoxicity tests for nanomedicines. J Control Release. 2013;172(2):456-466. doi:10. 1016/j.jconrel.2013.05.025

31. Food and Drug Administration [homepage on the Internet]. Estimating the maximum safe starting dose in initial clinical trials for therapeutics in adult healthy volunteers; 2005. Available from: https://www.fda.gov/ regulatory-information/search-fda-guidance-documents/estimatingmaximum-safe-starting-dose-initial-clinical-trials-therapeutics-adulthealthy-volunteers. Accessed January 20, 2019.

32. ASTM E2526-08(2013), Standard Test Method for Evaluation of Cytotoxicity of Nanoparticulate Materials in Porcine Kidney Cells and Human Hepatocarcinoma Cells. West Conshohocken, PA:ASTM International;2013. doi:10.1520/E2526-08R13.

33. Nanotechnology Characterization Laboratory [homepage on the Internet]. Stern ST, Adiseshaiah PP, Potter TM. NCL method GTA-2 hep G2 hepatocarcinoma cytotoxicity assay. Version 1.2. Available from: https://ncl.cancer.gov/resources/assay-cascadeprotocols. Accessed January 20, 2018.

34. Nanotechnology Characterization Laboratory [homepage on the Internet]. Potter TM, Neun BW, Rodriguez J, Ilinskaya AN, Dobrovolskaia MA. NCL method ITA-10 preparation of human whole blood and peripheral blood mononuclear cell cultures to analyze nanoparticle potential to induce inflammatory cytokines, chemokines and interferons in vitro. Version 1.2. Available from: https://ncl.cancer. gov/resources/assay-cascade-protocols. Accessed January 20, 2018.

35. EN ISO 10993-5:2009. Biological evaluation of medical devices Part 5: tests for in vitro cytotoxicity. Available from: www.iso.org. Accessed July 24, 2020.

36. ASTM E2524-08(2013). Standard test method for analysis of hemolytic properties of nanoparticles. West Conshohocken, PA:ASTM International; 2013. doi:10.1520/E2524-08R13,

37. Banerjee N, Sengupta S, Roy A, Ghosh P, Das K, Das S. Functional alteration of a dimeric insecticidal lectin to a monomeric antifungal protein correlated to its oligomeric status. PLoS One. 2011;6(4): e18593. doi:10.1371/journal.pone. 0018593

38. Lima J, Sarmento RR, Souza J, et al. Evaluation of hemagglutination activity of chitosan nanoparticles using human erythrocytes. Biomed Res Int. 2015;2015.

39. Stavitsky AB, Jarchow C. Micromethods for the study of proteins and antibodies: I. Procedure and general applications of hemagglutination and hemagglutination-inhibition reactions with tannic acid and protein-treated red blood cells. J Immunol. 1954;72(5):360-367.

40. Nanotechnology Characterization Laboratory [homepage on the Internet]. Neun BW, Ilinskaya AN, Dobrovolskaia MA. NCL method ITA-5.1 qualitative analysis of total complement activation by western blot. Version 1.2. Available from: https://ncl.cancer.gov/ resources/assay-cascade-protocols. Accessed January 20, 2018.

41. Nanotechnology Characterization Laboratory [homepage on the Internet]. Rodriguez J, Neun BW, Ilinskaya AN, Dobrovolskaia MA. NCL method ITA-2.2 analysis of platelet aggregation by light transmission aggregometry. Version 1.2. Available from: https://ncl.cancer.gov/ resources/assay-cascade-protocols. Accessed January 20, 2018.
42. Nanotechnology Characterization Laboratory [homepage on the Internet]. Rodriguez J, Neun BW, Ilinskaya AN, Dobrovolskaia MA. NCL method ITA-2.1 analysis of platelet aggregation by cell counting. Version 1.2. Available from: https://ncl.cancer.gov/resources/assaycascade-protocols. Accessed January 20, 2018.

43. Nanotechnology Characterization Laboratory [homepage on the Internet]. Rodriguez J, Neun BW, Ilinskaya AN, Dobrovolskaia MA. NCL method ITA-12 analysis of nanoparticle effects on plasma coagulation times in vitro. Version 1.2. Available from: https://ncl.cancer. gov/resources/assay-cascade-protocols. Accessed January 20, 2018.

44. Nanotechnology Characterization Laboratory [homepage on the Internet]. Rodriguez J, Neun BW, Ilinskaya AN, Dobrovolskaia MA. NCL method ITA-7 detection of nitric oxide production by the macrophage cell line RAW264.7. Version 1.2. Available from: https://ncl.cancer.gov/resources/assay-cascadeprotocols. Accessed January 20, 2018.

45. Nanotechnology Characterization Laboratory [homepage on the Internet]. Stern ST, Zolnik BS. NCL method GTA-7 hepatocyte primary ROS assay. Version 1.1. Available from: https://ncl.cancer. gov/resources/assay-cascade-protocols. Accessed January 20, 2018.

46. Ginzburg AL, Truong L, Tanguay RL, Hutchison JE. Synergistic toxicity produced by mixtures of biocompatible gold nanoparticles and widely used surfactants. ACS Nano. 2018;12(6):5312-5322. doi:10.1021/acsnano.8b00036

47. Nadesh RND, P R S, Vadakumpully S, et al. Hematotoxicological analysis of surface-modified and -unmodified chitosan nanoparticles. J Biomed Mater Res A. 2013;101(10):2957-2966. doi:10.1002/jbm. a.34591

48. International Organization for Standardization [homepage on the Internet]. ISO/TC 229 nanotechnologies. Available from: https:// www.iso.org/committee/381983/x/catalogue/. Accessed January 20, 2018.

49. American Society for Testing and Materials [homepage on the Internet]. Nanotechnology standards. Available from: https://www. astm.org/Standards/nanotechnology-standards.html. Accessed January 20, 2018.

50 . Shen J, Hilgenbrink AR, Xia W, et al. Folate receptor- $\beta$ constitutes a marker for human proinflammatory monocytes. J Leukoc Biol. 2014;96(4):563-570. doi:10.1189/jlb.2AB0713-372R

51. Yang C, Gao S, Kjems J. Folic acid conjugated chitosan for targeted delivery of siRNA to activated macrophages in vitro and in vivo. J Mater Chem B. 2014;2(48):8608-8615. doi:10.1039/C4TB01374C

52. Wang X, Yao S, Ahn H-Y, et al. Folate receptor targeting silica nanoparticle probe for two-photon fluorescence bioimaging. Biomed Opt Express. 2010;1(2):453-462. doi:10.1364/BOE.1.000453

53. Contini C, Schneemilch M, Gaisford S, Quirke N. Nanoparticlemembrane interactions. $J$ Exp Nanosci. 2018;13(1):62-81. doi:10.1080/17458080.2017.1413253

54. Lin J, Alexander-Katz A. Cell membranes open "doors" for cationic nanoparticles/biomolecules: insights into uptake kinetics. ACS Nano. 2013;7(12):10799-10808. doi:10.1021/nn4040553

55. Leroueil PR, Berry SA, Duthie K, et al. Wide varieties of cationic nanoparticles induce defects in supported lipid bilayers. Nano Lett. 2008;8(2):420-424. doi:10.1021/n10722929

56. Hong S, Leroueil PR, Janus EK, et al. Interaction of polycationic polymers with supported lipid bilayers and cells: nanoscale hole formation and enhanced membrane permeability. Bioconjug Chem. 2006;17(3):728-734. doi:10.1021/bc060077y

57. Jiang H-L, Kim Y-K, Arote R, et al. Mannosylated chitosan-graftpolyethylenimine as a gene carrier for raw 264.7 cell targeting. Int $J$ Pharm. 2009;375(12):133-139. doi:10.1016/j.ijpharm.2009. 03.033

58. Xiao B, Ma P, Ma L, et al. Effects of tripolyphosphate on cellular uptake and RNA interference efficiency of chitosan-based nanoparticles in Raw 264.7 macrophages. $J$ Colloid Interface Sci. 2017;490:520-528. doi:10.1016/j.jcis.2016.11.088 
59. Yang Y, Xing R, Liu S, et al. Immunostimulatory effects of sulfated chitosans on RAW 264.7 mouse macrophages via the activation of PI3 K/Akt signaling pathway. Int $J$ Biol Macromol. 2018;108:1310-1321. doi:10.1016/j.ijbiomac.2017.11.042

60. Martínez-Torres AC, Zarate-Triviño DG, Lorenzo-Anota HY, ÁvilaÁvila A, Rodríguez-Abrego C, Rodríguez-Padilla C. Chitosan gold nanoparticles induce cell death in HeLa and MCF-7 cells through reactive oxygen species production. Int $J$ Nanomed. 2018;13:3235-3250. doi:10.2147/IJN.S165289

61. Alinejad V, Somi MH, Baradaran B, et al. Co-delivery of IL17RB siRNA and doxorubicin by chitosan-based nanoparticles for enhanced anticancer efficacy in breast cancer cells. Biomed Pharmacother. 2016;83:229-240. doi:10.1016/j.biopha.2016.06.037

62. Balan V, Verestiuc L. Strategies to improve chitosan hemocompatibility: a review. Eur Polym J. 2014;53:171-188. doi:10.1016/j. eurpolymj.2014.01.033

63. Dobrovolskaia MA, Aggarwal P, Hall JB, McNeil SE. Preclinical studies to understand nanoparticle interaction with the immune system and its potential effects on nanoparticle biodistribution. Mol Pharm. 2008;5(4):487-495. doi:10.1021/mp800032f

64. Fan W, Yan W, Xu Z, Ni H. Erythrocytes load of low molecular weight chitosan nanoparticles as a potential vascular drug delivery system. Colloids Surf B Biointerfaces. 2012;95:258-265. doi:10.1016/j.colsurfb.2012.03.006

65. Nanotechnology Characterization Laboratory [homepage on the Internet]. Clogston JD. NCL method PCC-2 measuring zeta potential of nanoparticles. Version 1.1. Available from: https://ncl.cancer.gov/ resources/assay-cascade-protocols. Accessed January 20, 2018.

66. Shankar E, Ramasubramanian A. Hemocompatibility of Nanoparticles. In: Sitharaman B, editor. Nanobiomaterials handbook. CRC Press; 2016:1-31.

67. Elsabahy M, Wooley KL. Cytokines as biomarkers of nanoparticle immunotoxicity. Chem Soc Rev. 2013;42(12):5552-5576. doi:10.1039/c3cs60064e

68. Feghali CA, Wright TM. Cytokines in acute and chronic inflammation. Front Biosci. 1997;2(1):d12-d26. doi:10.2741/A171

69. O'Shea JJ, Murray PJ. Cytokine signaling modules in inflammatory responses. Immunity. 2008;28(4):477-487. doi:10.1016/j.immuni. 2008.03.002

70. Bueter CL, Lee CK, Wang JP, Ostroff GR, Specht CA, Levitz SM. Spectrum and mechanisms of inflammasome activation by chitosan. $J$ Immunol. 2014;192(12):5943-5951. doi:10.4049/jimmunol. 1301695

71. Feng J, Zhao L, Yu Q. Receptor-mediated stimulatory effect of oligochitosan in macrophages. Biochem Biophys Res Commun. 2004;317(2):414-420. doi:10.1016/j.bbrc.2004.03.048

72. Fong D, Hoemann CD. Chitosan immunomodulatory properties: perspectives on the impact of structural properties and dosage. Future Sci OA. 2017;4(1):FSO225. doi:10.4155/fsoa-2017-0064
73. Carroll EC, Jin L, Mori A, et al. The vaccine adjuvant chitosan promotes cellular immunity via DNA sensor cGAS-STINGdependent induction of type I interferons. Immunity. 2016;44 (3):597-608. doi:10.1016/j.immuni.2016.02.004

74. Azuma K, Osaki T, Minami S, Okamoto Y. Anticancer and anti-inflammatory properties of chitin and chitosan oligosaccharides. J Funct Biomater. 2015;6(1):33-49. doi:10.3390/jfb6010033

75. Beyerle A, Irmler M, Beckers J, Kissel T, Stoeger T. Toxicity pathway focused gene expression profiling of PEI-based polymers for pulmonary applications. Mol Pharm. 2010;7(3):727-737. doi:10.1021/mp900278x

76. Manke A, Wang L, Rojanasakul Y. Mechanisms of nanoparticle-induced oxidative stress and toxicity. Biomed Res Int. 2013;2013:942916. doi:10.1155/2013/942916

77. Ngo D-H, Vo T-S, Ngo D-N, et al. Biological effects of chitosan and its derivatives. Food Hydrocoll. 2015;51:200-216. doi:10.1016/j. foodhyd.2015.05.023

78. Qiao Y, Bai X-F, Du Y-G. Chitosan oligosaccharides protect mice from LPS challenge by attenuation of inflammation and oxidative stress. Int Immunopharmacol. 2011;11(1):121-127. doi:10.1016/j. intimp.2010.10.016

79. Bai R, Yong H, Zhang X, Liu J, Liu J. Structural characterization and protective effect of gallic acid grafted O-carboxymethyl chitosan against hydrogen peroxide-induced oxidative damage. Int $\mathrm{J}$ Biol Macromol. 2020;143:49-59. doi:10.1016/j.ijbiomac.2019.12.037

80. Jesus S, Marques AP, Duarte A, et al. Chitosan nanoparticles: shedding light on immunotoxicity and hemocompatibility. Front Bioeng Biotechnol. 2020;8:100. doi:10.3389/fbioe.2020.00100

81. Sarangapani S, Patil A, Ngeow YK, Elsa Mohan R, Asundi A, Lang MJ. Chitosan nanoparticles' functionality as redox active drugs through cytotoxicity, radical scavenging and cellular behaviour. Integr Biol. 2018;10(5):313-324. doi:10.1039/C8IB00038G

82. Xu Q, Liu M, Liu Q, Wang W, Du Y, Yin H. The inhibition of LPS-induced inflammation in RAW264. 7 macrophages via the PI3K/ Akt pathway by highly N-acetylated chitooligosaccharide. Carbohydr Polym. 2017;174:1138-1143. doi:10.1016/j.carbpol.2017.07.051

83. Food and Drug Administration [homepage on the Internet]. Nanotechnology/nanotoxicology; 2019. Available from: https:// www.fda.gov/medical-devices/cdrh-research-programs/nanotechnolo gynanotoxicology. Accessed October 10, 2019.

84. Food and Drug Administration [homepage on the Internet]. Nanotechnology task force report; 2007. Available from: https:// www.fda.gov/science-research/nanotechnology-programs-fda/nano technology-task-force-report-2007\#definitions. Accessed January 20, 2019.

85. ISO/TR 10993-22:2017. Biological evaluation of medical devices part 22: guidance on nanomaterials. Available from: www.iso.org. Accessed July 24, 2020.
International Journal of Nanomedicine

\section{Publish your work in this journal}

The International Journal of Nanomedicine is an international, peerreviewed journal focusing on the application of nanotechnology in diagnostics, therapeutics, and drug delivery systems throughout the biomedical field. This journal is indexed on PubMed Central, MedLine, CAS, SciSearch ${ }^{\mathbb{R}}$, Current Contents ${ }^{\mathbb{R}} /$ Clinical Medicine, $^{2}$
Journal Citation Reports/Science Edition, EMBase, Scopus and the Elsevier Bibliographic databases. The manuscript management system is completely online and includes a very quick and fair peer-review system, which is all easy to use. Visit http://www.dovepress.com/ testimonials.php to read real quotes from published authors. 